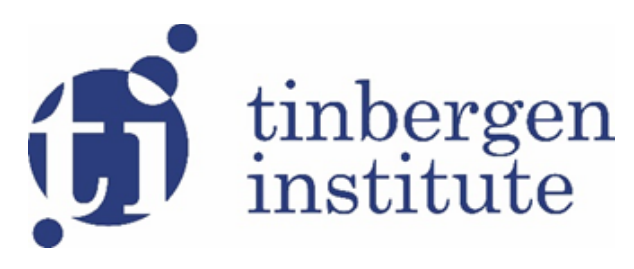

TI 2020-010/IV

Tinbergen Institute Discussion Paper

\title{
Multiple buffer CoCos and their impact on financial stability
}

Ioana Neamtu ${ }^{1}$

\footnotetext{
${ }^{1}$ University of Amsterdam
} 
Tinbergen Institute is the graduate school and research institute in economics of Erasmus University Rotterdam, the University of Amsterdam and VU University Amsterdam.

Contact: discussionpapers@tinbergen.nl

More TI discussion papers can be downloaded at https://www.tinbergen.nl

Tinbergen Institute has two locations:

Tinbergen Institute Amsterdam

Gustav Mahlerplein 117

1082 MS Amsterdam

The Netherlands

Tel.: +31(0)205984580

Tinbergen Institute Rotterdam

Burg. Oudlaan 50

3062 PA Rotterdam

The Netherlands

Tel.: +31(0)10408 8900 


\title{
Multiple buffer CoCos and their impact on financial stability
}

\author{
Click here tor most recent version
}

Ioana NEAMȚU

January 29, 2020

\begin{abstract}
In this paper we develop a theoretical model to investigate the effect on a bank's financial stability of having multiple contingent convertible bonds buffers (CoCos) on the same bank balance sheet, using cash-in-the-market pricing and global games methodologies. Contingent convertible bonds are meant to act as a bail-in mechanism for banks, where CoCo debt converts into equity when a bank needs it the most. We find that having CoCo buffers which trigger at different capitalisation levels can be detrimental for the CoCo bail-in capacity. Market-based triggers lead to premature conversion and fire-sales of equity. In contrast with existing literature, we show that book-based trigger CoCos yield an optimal outcome, as long as they incorporate expected credit losses.
\end{abstract}

Keywords: contingent convertible bonds, fire sales, financial stability JEL Classification: G21, G32, G38

*University of Amsterdam, Tinbergen Institute Ineamtı(@)va.n!

†I am most grateful to my supervisor Sweder van Wijnbergen for his suggestions and support throughout the process. I thank discussants and seminar participants from various conferences and seminars for their valuable feedback and suggestions. This paper has been previously circulated as "Instabilities of two-layered CoCo capital structures". 


\section{Introduction and related literature}

In 2013, the Swiss National Bank (SNB) imposed additional requirements on bank capitalisation for Systemically Important Financial Institutions (SIFIs) in addition to Basel III regulation. Besides increased minimum levels of capitalisation, a distinct element of Basel III compared to past regulation is the introduction of Contingent Convertible bonds (CoCos), a security which is meant to act as a bail-in mechanism for banks in times of distress. CoCos are a hybrid security which act as a bond, but convert immediately into equity or are (partially) written down if the bank reaches, or is below, a pre-specified threshold which signals a poor financial state of the issuing body. In the 'Swiss finish', SNB imposes a higher capitalisation level of going-concern CoCos and unlike Basel III, a higher minimum trigger level. The CoCo IPOs of the two SIFI Swiss banks - Credit Suisse AG and UBS AG - indicate that the banks still work towards filling in the minimum requirements on high trigger CoCos (in end 2017), but they still hold, or even issue new low trigger CoCos on their balance sheet. To the best of our knowledge, these two groups are the only two banks worldwide to hold a two-layered going-concern CoCo structure on the same set of assets, which indicates to us that they only exist to meet regulatory requirements, and do not necessarily arise as part of an optimal banks' capital structure (Avdjiev et al., 2015). The novelty of a bank having two different going-concern trigger levels in the capital structure has not yet been discussed in the literature, but their treatment in case of conversion has been incorporated in the European Banking Authority report (EBAReport, खात) प.

To the best of our knowledge, the effects of this multiple buffer strategy on financial stability have not yet been researched, even though it is implemented and advocated as a safe bail-in mechanism. The aim of this paper is two-fold. Our overarching research question is to analyse the effects of CoCo conversion on subsequent CoCo bail-in capacity in case of multiple buffer CoCo bank capital structures. Secondly, we aim to find an optimal CoCo design which minimises inefficient conversion, for a given capital structure. By 'inefficient' we understand that conversion occurs above the bank fundamentals trigger threshold.

\footnotetext{
1 The report stipulates the possibility that both CoCos are hit simultaneously. The sequencing is as follows: "losses corresponding to the amount required to go back to $5.125 \%$ should be absorbed by both the low trigger and the high trigger instruments on a pro rata basis. Losses above $5.125 \%$ will only be supported by the high trigger instrument" (Art. 96).
} 
In this paper we argue that there is a key trade-off in the two-layered structure of CoCo bonds. Multiple trigger levels effectively translate in multiple recapitalisation buffers on a going-concern basis, which increase bank resilience. Nonetheless, the triggering of the first buffer can be perceived as a strong market signal that the bank is in financial distress, leading to further market panic, which can artificially trigger subsequent CoCo buffers. Hence, the trade-off of several CoCo buffers that we aim to capture is increased bank resilience versus the possibility of fire sales of equity.

We show how CoCo design matters when a bank has to comply with regulatory requirements on an equity ratio, as it is currently stipulated in the Basel III regulations. To that end, we model decisions that are taken in industry, but have not yet been accounted for in the CoCos literature. We incorporate the pro-cyclicity of limited cash with the returns on assets, and assess how this co-movement affects equity. This paper falls under the banking literature that deals with unintended post-crisis regulation, and more specifically with the one of CoCo regulation in Basel III and beyond. Firstly, in order to maintain a particular equity to assets ratio, banks can either increase their equity base or decrease their asset side. Empirical evidence indicates that shrinking the balance sheet through asset liquidation is commonly done (Association for Financial Markets in Europe, एणr), aspect which we incorporate in the paper. De-leveraging is often observed as opposed to raising new capital in face of negative shocks to existing positions (Classens, 2014), as in times of distress equity is expensive to issue. We model the banks' choices as a constrained maximisation problem, in which the bank maximises the equity value while maintaining a minimum level of equity to assets ratio. Secondly, equity holders are affected by initial CoCo issuance and later on by asset pricing volatility due to the news impact that CoCos can create. Insofar, the focus in the literature has been placed on depositor bank runs (Chan and van Wijnbergen, 피. $)$, but we argue that the signaling value of CoCos can create a downward spiral on equity as well, aspect which was previously modeled in continuous time by Sundaresan and Wang (2015). They show multiplicity of equilibria in the presence of market triggers in discrete time, but they were further ruled out in continuous time (Glassserman and Vourl, 2016), and corrected by Pennacchi and Tchistyi (핌). Lastly, we introduce cash-in-the-market pricing in the CoCos literature: in times of distress there is not enough cash available in the market which in turn will depress the market prices of equity. We find that a two-layered CoCo capital structure leads to multiplicity of equilibria, no equilibrium 
or a unique (inefficient) equilibrium for CoCo conversion in times of distress. We further compare the optimality of different types of CoCo designs and show which one minimises the inefficient conversion space, for a fixed capital structure. We find that market based triggers, even though very popular in academic literature, harm the issuing bank either directly, through inefficient conversion of CoCos, or indirectly through an artificial speculative attack on forcing conversion by equity holders. In this context we show that a capital structure with two different types of CoCos is detrimental to the financial health of the bank, as the second (low trigger) CoCo will not successfully act as an additional buffer. Instead, the high trigger one can induce a negative externality of converting the low one as well through the equity holders reaction. In contrast, we argue that book based triggers can be an effective bail-in mechanisms as long as the value of assets is evaluated accurately by the issuing bank, and it incorporates expected losses. If the accounting value only accounts for occurred losses, as it is was stipulated in the International Financial Reporting Standards (IFRS) until 2018, then going concern CoCos do not fulfil any function on loss absorbing capacities before it is too late in our model. Nonetheless, this problem is mitigated with the incorporation of expected credit losses.

The paper is structured as follows. Firstly, we present a primer on CoCos and how this paper is embedded in the existent literature. In section 2 we define and solve the baseline model and economy. In section 3 we analyse the extended model of having two CoCo buffers and draw comparisons with the baseline model. Lastly, in section 4 a comparison between different types of CoCos follows, and the paper concludes.

\subsection{CoCo primer}

Contingent Convertible bonds have two key characteristics: the trigger which determines the conversion, and the type of conversion they will incur. A summary can be found in Figure $\boldsymbol{\square}$. The loss absorption mechanism can be either conversion to equity (CE hereafter) or a principal write-down (PWD hereafter). To generalize, let

the conversion rate be $\psi \in[0, \infty)$, per unit of CoCo, with conversion price $\frac{1}{\psi}$ (Chan and van Wijnbergen, 2017). The PWD CoCos are a limiting case, with conversion rate $\psi=0$. 
Figure 1

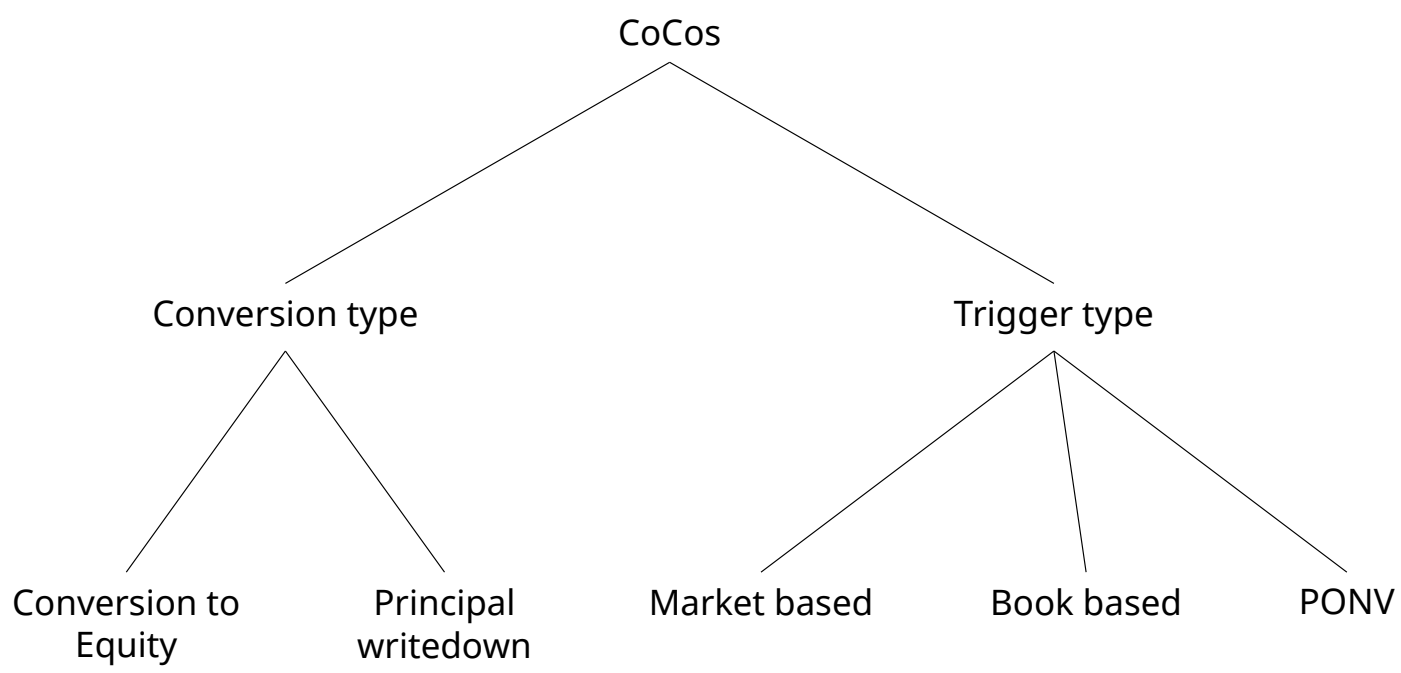

The trigger can be mechanical and/or discretionary. The discretionary trigger is activated at the point of non-viability of a bank (PONV). This feature allows the supervisor to force conversion if it considers it as a necessary step in preventing insolvency ${ }^{\square}$. The mechanical trigger imposes conversion at a pre-specified ratio of core capital to risk weighted assets (RWA). The key distinction between market and book based triggers is in measuring the value of core capital and RWA. Book value can be effective in terms of timely recapitalisation if it is measured correctly, and at a high frequency, while market value could capture inconsistent accounting valuations. We understand by correct measurement an accurate evaluation of asset value, which incorporates tail-risk events.

Under Basel III, CoCos can qualify as Additional Tier 1 (AT1 hereafter) or Tier 2 (T2) capital. To qualify as AT1 under European Law, the CoCos need to, among others: have a PONV clause, absorb losses on a going-concern basis, be perpetual

\footnotetext{
${ }^{2}$ Effects of conversion on equity holders or market prices are unclear, as the very first conversion happened only in June 2017 at Banco Popular, a Spanish bank which was taken over by Santander ( $\overline{\mathrm{Smith}}, \mathbf{D I I 7})$. The decision of a full write-down was made under PONV and imposed by the Single Resolution Board, part of the EU Banking Union. Financial Times argued that the conversion had little spillovers in the market, and some CoCo holders already accused the authority of lack of transparency and valuation of the resolution (Beardsworth, PONV clause, and do not model its additional effects on conversion prices.
} 
instruments and have a minimum trigger level of $5.125 \%$ of Core equity tier 1 (CET1) to RWA. Countries can stipulate additional conditions to the European Law minimum requirements. For instance, Denmark and UK imposed a minimum trigger level of $7 \%$ for AT1 instruments. The Swiss national supervisors request at least 6 percent of 'low-trigger' AT1 or T2 CoCos and an additional 4.3 percent of 'high-trigger' AT1 CoCos (Swiss Financial Market Supervisory Authority, 피. $)$. Tier 2 CoCos and further regulatory requirements are beyond the scope of this paper, but a more comprehensive analysis can be found in Avdjiev et al. (सII.3), Avdijev et al. (201]) and Klewlet et al. (सII)

\section{Related literature}

The dominant views on the CoCo issuance are either for meeting regulatory requirements (Avdjiev et al., 201.3 ) or emerging as an optimal capital structure of a bank for risk shifting incentives. Our paper belongs to the former strain, where banks issue them only to meet regulatory requirements, and have additional bail-in buffers.

There has been an extensive theoretical literature on CoCos after their introduction after the financial crisis. The focus in the literature has been on depositor runs (see Chan and van Wijnbergen (खII)), managerial risk shifting incentives ( see

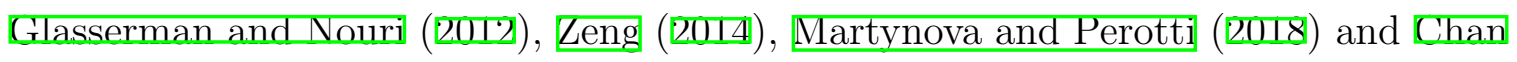
and van Wijnbergen (JI7) ). The closest models to our framework are the ones by Avdijev et al. (IIT) and Chan and van Wijnbergen (iII. ).

If market participants have noisy information about the true state of nature, methodologies on self-fulfilling crisis use global strategic complementarities or adverse selection (impatient and patient agents with need to withdraw) (Morris and Shm,

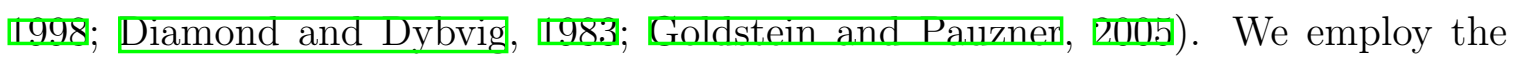
bank-run methodology of Gnddstein and Pallzner (피.5) to prove uniqueness of the inefficient equilibrium, below which crises are self-fulfilling. A similar approach based on global games has been done by Chan and van Wijnbergen (《II.5) on depositor runs, but our focus is on equity. To the best of our knowledge, we are the first to introduce limited cash availability in the market in a CoCos model. We exemplify the impact of market liquidity on pricing stocks using the liquidity shocks from the seminal paper of Allen and (iale (IT94).

The existent debate in the literature on CoCo trigger levels focuses almost ex- 
clusively on market based triggers. Glasserman and Vouri (खII) and Derksen et aL (सIII) develop valuation models in continuous time for CoCos based on book value. Nonetheless, in industry all financial institutions have a book-based trigger. In Europe market based triggers are outlawed by the Capital Requirements Regulation (CRR). The downward equity spiral aspect was previously modeled in continuous time by Sundaresan and Wang (피). They argue against regulation which uses a CoCo trigger based on market value, because it can create instability in the market and lead to multiplicity of equillibria in pricing the assets. Their multiple equillibria were obtained using discrete time, and were further ruled out in continuous time

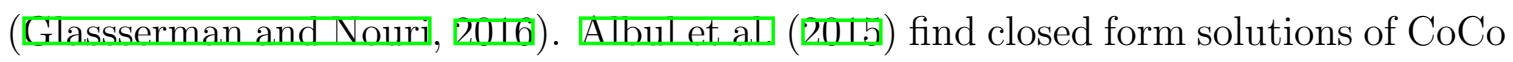
prices in continuous time of optimal capital structure when market trigger CoCos are a choice variable. Their objective function is maximizing equity value, and show how different structures affect leverage, bankruptcy costs and tax benefits.

\section{Model setup}

The framework is based on a theoretical three period model $t=\{1,2,3\}$, with a bank, and three types of agents: private investors, passive bank debt holders, a bank manager, and two main frictions: fire sales of equity (cash-in-the-market) pricing of equity and an unexpected shock to asset returns. The economy is described by its fundamentals $\theta \sim \operatorname{Unif}[0,1]$, where a low value of $\theta$ indicates a bad state of the world. $\theta$ is realised at $t=2$, but each market participant $i \in\{1,2,3, \ldots, n\}$ only obtains a noisy signal $\theta_{i}=\theta+\varepsilon_{i}$ about its true value, where the noise is drawn from a uniform distribution $\varepsilon_{i} \in U$ nif $[-\varepsilon, \varepsilon]$.

\subsection{Baseline model}

We start with the most general case, where the bank has only one layer of CoCo debt, and it faces a strong informational shock in the intermediate period which alerts the market about the possibility of CoCo conversion.

\subsubsection{Bank capital structure}

We assume an exogenous bank capital structure, in place before $t=1$, consisting of a risky asset, and liabilities in the form of senior debt, CoCo debt and equity. We 
justify this simplifying case of exogeneity based on CoCo regulation being introduced on existing capital structures. The bank invests ex-ante an amount $A$ in a risky investment ${ }^{\mathbf{D}}$ - see Table $\boldsymbol{\square}$. The risky investment has returns at $t=3$, and depend on the initial asset riskiness - determined by the variance of returns, and the state of economic fundamentals $\theta$. The returns follow a general probability distribution function $f_{A}(\theta)$, with a cumulative distribution function $F_{A}(\theta)$, and a corresponding standard deviation $\sigma_{A}$. The expected value from the investment decision perspective is $E_{t=0}[A]=\int_{\theta=0}^{\theta=1} A \theta f_{A}(\theta) d \theta=R>1$. The long term risky asset can be liquidated early in the intermediate period $t=2$. Early liquidation is costly, and the entire asset can be liquidated for a value $l$, where $l<E[A]$.

To fund its investment, the bank raises a total amount outstanding of senior debt $D$, CoCo debt $C$, and equity $e_{0}$. CoCo debt has a conversion rate of $\psi$ and a trigger level $\tau$. The conversion is dependent on the ratio of equity to risk weighted assets. If the ratio is below $\tau$, then the CoCo debt will convert. All debt is repaid at $t=3$ and equity holders $e_{0}=A-D-C$ receive dividends. Further, let $e_{t}^{m}$ denote the market equity capitalisation evaluated at $t=\{1,2,3\}$, and $e_{t}^{b}$ the corresponding book capitalisation at time $t$.

\section{Capital requirement for $\mathrm{CoCos}$}

The bank is subject to a risk-based capital requirement (RWA) at each time period. The regulatory requirement imposes a minimum level of equity to be held against the total value of risk weighted assets.In case this ratio falls below the minimum requirement $\tau$, then CoCo debt converts and acts as an internal bail-in mechanism. If equity is book-based evaluated, then the requirement reads:

$$
R W A_{\text {book }}=\frac{E[A]-D-C}{\sigma_{A} E[A]}>\tau
$$

\footnotetext{
${ }^{3}$ We assume that the bank does not hold any cash ex-ante. We solved the model with cash on the balance sheet of the bank as well, but the main results do not change and just add additional notation.

${ }^{4}$ For the purpose of this setup the shape of the distribution function does not affect the results.

${ }^{5}$ We assume throughout deposit insurance, and so we do not consider depositor runs. We abstract from this matter by completely excluding demandable debt in the capital structure of the bank. For a global games analysis of potential CoCo impact on depositor runs, see Chan and van Wijnbergen (खII5).
} 
Alternatively, if equity is evaluated on the market, the numerator is given by the market capitalisation $e^{m}=P_{m} n_{\max }$, where $P_{m}$ is the market price per share, and $n_{\max }$ is the number of shares. In this case, the constraint reads:

$$
R W A_{\text {market }}=\frac{P_{m} n_{\max }}{\sigma_{A} E[A]}>\tau
$$

If the bank is priced at fair value, then the book and market based requirements coincide - equations $(\mathbb{G})$ and $(\boldsymbol{\nabla})$ are equivalent. In case of distress, the ratio can be maintained either through costly liquidation of long term assets, or by CoCo conversion. The other alternative is issuing new equity, but we argue that this is the least appealing for the bank in times of crisis, due to underpricing and dilution of existing shareholders.

Table 1: Initial balance sheet baseline model

\begin{tabular}{l|l}
\hline Assets & Liabilities \\
\hline A - initial investment & $\mathrm{D}$-senior debt \\
& $C$ - CoCo debt \\
& $e_{0}$ - initial equity \\
\hline
\end{tabular}

\subsubsection{Agents}

There are three types agents of in the economy: active investors, bank manager and passive debt holders.

\section{Investors}

There is a unit mass risk-neutral investors with wealth $W=c+e_{0}$ divided ex-ante between cash $c$ and equity $e_{0}$. These investors know ex-ante the existence of the idiosyncratic shock, but they do not know the magnitude (as it is dependent on yet unknown $\theta$ ), hence they self-insure by holding both cash and equity. They are the only ones to hold bank equity, and their decisions are going to determine the (fire sale) share price in the market at $t=2$. At $t=2$ fraction $\lambda(\theta) \in(0,1)$ of investors is hit by a liquidity shock. Each investor $i \in\{1,2, \ldots n\}$ and the bank manager $B$ obtain a noisy signal $\theta_{i}=\theta+\varepsilon_{i}, \theta_{B}=\theta+\varepsilon_{B}$ respectively, where $\varepsilon_{i}$ is the information noise drawn from a uniform distribution $\operatorname{Unif}[-\varepsilon, \varepsilon]$. 
The fraction of investors $\lambda(\theta)$ hit by the liquidity shock sell their equity. The investors $1-\lambda(\theta)$ not hit by the shock decide whether to sell or not their stake in the bank. The consumption decision of the late investors depends on the market price of equity today versus the expected dividend payments of tomorrow, which depend on own signal $\theta_{i}$, and how many other market participants sell at $t=2$. We denote the fraction of late investors which sell by $\lambda_{\text {panic }}(\theta) \in(0,1-\lambda(\theta))$. This framework which will further drive our cash-in-the-market pricing results is based on the seminal work of Allen and (Gale (1994). The investor decisions to sell or buy bank equity at the intermediate stage determine the equilibrium share price on the market $P^{m}$.

\section{Bank manager}

The bank manager has no initial wealth, and their aim is to maximise banks' share value while meeting the risk-sensitive capital requirements at $t=\{1,2\}$. In case of recapitalisation needs, the bank's choice is between asset substitution or Coco conversion. In the baseline model, the manager faces a decision only at the intermediate time $t=2$ after the price of equity is pinpointed in the market.

The decision of the manager is to maximise shareholders' value, by choosing the optimal liquidation fraction and conversion, conditional on meeting the risk-based capital requirement. In case of market based requirements, the banks' manager problem reads:

$$
\begin{aligned}
& \max _{\beta, \mathbb{1}_{\text {conv }}} \frac{e^{b}}{n_{\text {max }}}=\frac{\left(1-\mathbb{1}_{\text {conv }} \beta\right) E[A]+\mathbb{1}_{\text {conv }} \beta l-\mathbb{1}_{\text {conv }} C-D}{n_{\text {max }}} \text { s.t. } \\
& R W A=\frac{P^{m} n_{\text {max }}}{\sigma_{A}\left(1-\mathbb{1}_{\text {conv }} \beta\right) E[A]} \geq \tau
\end{aligned}
$$

where $\beta \in[0,1]$ is the liquidation fraction of long term assets, $l<1$ liquidation value per unit of investment and $\mathbb{1}_{\text {conv }}$ is an indicator function for conversion:

$$
\mathbb{1}_{\text {conv }}= \begin{cases}0 & \text { if conversion of low CoCo } \\ 1 & \text { otherwise }\end{cases}
$$

The maximum number of shares, $n_{\max }=1+\left(1-\mathbb{1}_{\text {conv }}\right) \psi C$ Alternatively, when the requirement is book based, the numerator $P^{m} n_{\max }$ is replaced with the book value of equity. 


\section{Passive debt holders}

The third type of agents are passive bond holders, which hold debt in the bank either in the form of senior or CoCo debt. They do not play an active role in the subsequent analysis, as their behavior on the secondary market does not influence equilibrium outcomes in this setting.

\subsubsection{Timeline}

Figure 2: Timeline baseline model

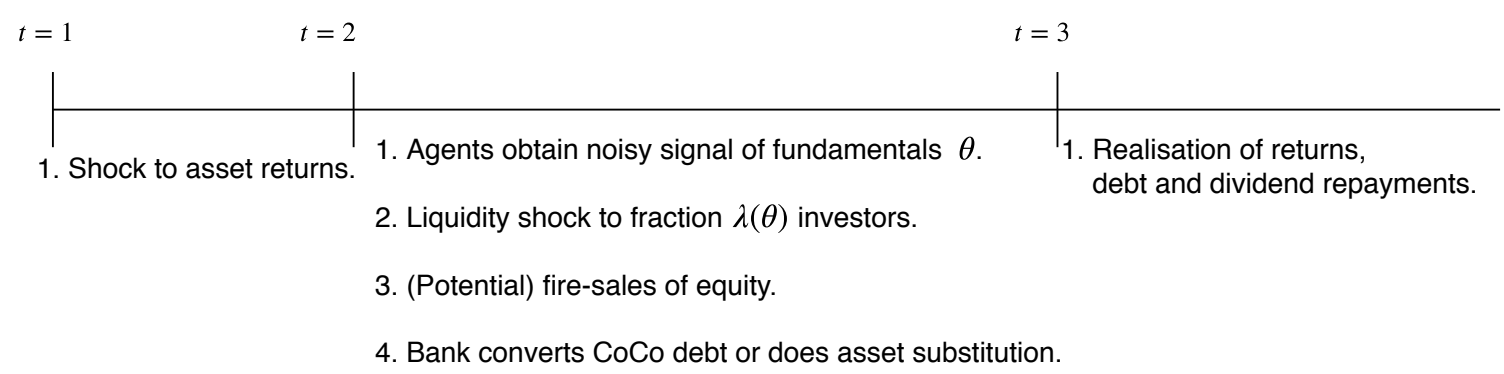

Ex-ante, the bank raises funds, and investors allocate their portfolio $W=c+e_{0}$.

At $t=1$ there is new private information revealed about the risky assets, which decreases the expected value of returns to the risky asset from $\mathrm{R}$ to $R_{L}$. We model this new information as a first order stochastic dominance shift in the probability distribution of returns of the long term asset from $f_{A}(\theta)$ to $f_{L}(\theta): E_{1}\left[A \mid f_{L}\right]=R_{L}<R$, thus maintaining the same standard deviation $\sigma_{A}$. The bank manager incorporates this information at time $t=1$ in the capitalisation requirement, which becomes:

$$
R W A_{1}=\frac{E_{1}\left[A \mid f_{L}\right]-D-C}{\sigma_{A} E_{1}\left[A \mid f_{L}\right]}>\tau
$$

The new ratio is still higher than the minimum capital requirement, but the shock is large enough to be observed in the market. This signals to the market that returns are lower than initially expected which potentially influence the behaviour of equity holders at $t=2$.

At $t=2$, the true state of fundamentals $\theta$ is realized. Each investor $i \in\{1,2, \ldots n\}$ and the bank $B$ obtain noisy signals $\theta_{i}=\theta+\varepsilon_{i}$, where $\varepsilon_{i}$ is the information noise 
Figure 3: Decision tree baseline model

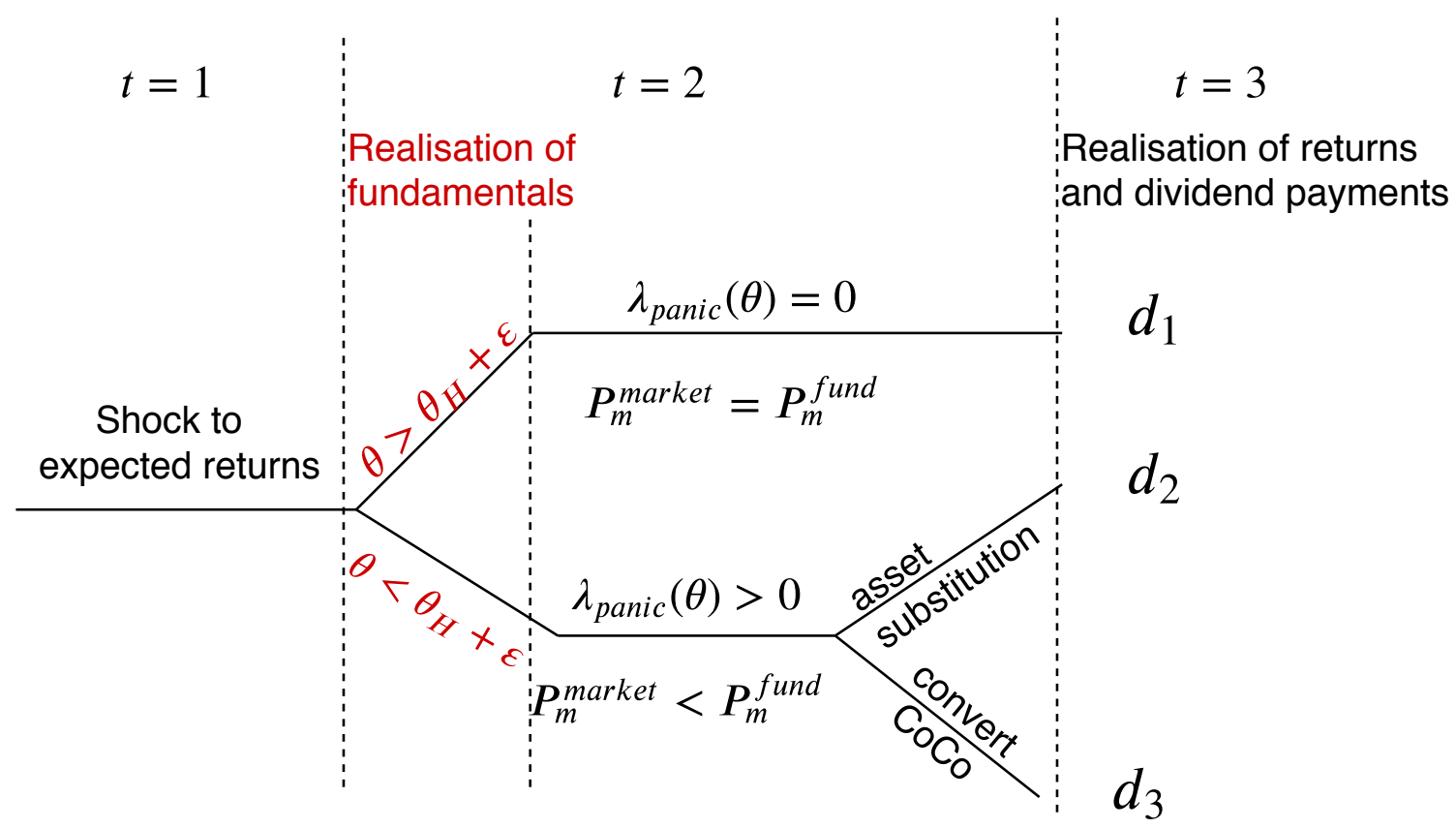

drawn from a uniform distribution Unif $[-\varepsilon, \varepsilon]$. A fraction $\lambda(\theta)$ of investors are hit by a liquidity shock and sell their equity. Due to the asset shock at $t=1$ existing equity holders expect lower returns, but also a potential CoCo conversion or asset substitution. If the fundamentals are perceived as good enough, so the worst signal that an investor obtains is $\theta_{H}$, and so the fundamentals are higher than $\theta_{H}+\varepsilon$, then the expected returns are high enough to have no investors which sell equity without having a liquidity need. Otherwise, there is a fraction of investors $\lambda_{\text {panic }}(\theta)$ who sell their equity in light of these potential effects, and we refer to them as panic investors.

After markets clear, and the price of equity is determined, the bank manager reevaluates the $R W A$ requirement. The manager maximises share value, while meeting the capitalisation requirements. They re-establish the capitalisation ratio either by asset substitution or high CoCo conversion.

At $t=3$ returns on the long term asset are realized and debt and dividend payments are made.

To summarise, there are two signals in the economy. At $t=1$ the manager obtains new private information about the distribution of returns to the long term asset. The second signal is represented by the noisy information about the state of 
fundamentals $\theta$ at $t=2$. The shock to assets and the state of the fundamentals are uncorrelated.

If fundamentals are good enough: $\theta>\theta_{H}+\varepsilon$, then there are no panicked investors, and equity trades at book/fundamental prices: $P^{m}=P^{b o o k}$. Otherwise, there are panicked investors and equity trades below book value. We depict this decision tree mechanism in Figure $\mathbf{1}$. The possible dividend payoffs at $t=3$ are $\left(d_{1}, d_{2}, d_{3}\right)$ corresponding to the three states of the world.

\subsection{Baseline model equilibrium analysis}

We solve for equilibrium using backward induction, and derive the optimal strategy of the bank manager, and of late investors $\lambda_{\text {panic }}^{*}(\theta)$ at $t=2$. The most interesting case is the one when the ratio is evaluated in the market, and so we solve for equilibrium for the baseline model only for that case. In the extension with two CoCo buffers we treat also the book ratio case. We start by deriving the market clearing price of equity, followed by banks' best response to it, and the investors' decision.

\subsubsection{Market clearing price of equity}

At $t=1$, the bank manager received additional information that the expected returns on the risky asset are lower than expected. They incorporate it in the value of risk weighted assets. As there is too little information about the state of the world - $\theta$ is unknown, and none of the investors is hit by a shock yet, we assume that equity is traded at fundamental value.

At $t=2$ the market clearing price of shares is endogenously determined by the cash availability in the market. Let $P^{m}$ be the market clearing price per share at time $t=2$, and $n_{\max }$ is the total number of shares the bank has, and is defined as

$$
n_{\max }= \begin{cases}1 & \text { if no conversion } \\ 1+\psi C & \text { if CoCo debt converts }\end{cases}
$$

Proportion $\lambda(\theta)$ of initial investors face at $t=2$ a liquidity shock, and they have to consume. The function $\lambda(\theta):[0,1] \rightarrow[0,1]$ is continuous and monotonically decreasing in $\theta$. This captures that more investors require liquidity as the economic state worsens. All investors hit by the shock sell their stake in the bank, regardless of 
the market price. There are $0<\lambda_{\text {panic }}(\theta)<1-\lambda(\theta)$ fraction of panic investors which are not hit by the liquidity shock, but they still decide to sell equity at $t=2$. Thus, there are three types of investors at $t=2: \lambda(\theta)$ of early investors who are hit by a shock and have to sell, $\lambda_{\text {panic }}(\theta)$ late investors who are not hit by a shock but still decide to sell (panicked agents), and $1-\lambda(\theta)-\lambda_{\text {panic }}(\theta)$ who are not hit by a shock and do not sell, but instead buy all the equity in the market. The available cash in the market is determined by the late investors which wait for dividend payments: $\left[1-\lambda_{\text {panic }}(\theta)-\lambda(\theta)\right] c$. Their preference of buying equity is trivially satisfied, as in case the equity sells at fundamental value they are indifferent, and if it sells at a depressed price then they are better-off buying, given their beliefs. The market capitalisation must be lower then or equal to the available cash in the market. Thus, the market clearing condition at $t=2$ satisfies:

$$
P^{m}(\theta)\left[\lambda(\theta)+\lambda_{\text {panic }}(\theta)\right] e_{0} \leq\left[1-\lambda(\theta)-\lambda_{\text {panic }}(\theta)\right] c
$$

Corollary 1. At $t=2$, shares are either traded at fundamental value, or below it. The market clearing price in the stock market is:

$$
P^{m}\left(\lambda(\theta), \lambda_{\text {panic }}(\theta)\right)=\min \left[\frac{e_{1}^{b}}{n_{\max }}, \frac{\left[1-\lambda(\theta)-\lambda_{\text {panic }}(\theta)\right] c}{\left[\lambda(\theta)+\lambda_{\text {panic }}(\theta)\right] e_{0} \cdot n_{\text {max }}}\right]
$$

where $n_{\max }$ is the initial number of shares, and $e_{1}^{b}$ represents the book value of equity at $t=1$.

\subsubsection{Banks' best response}

Once the equilibrium price $P^{m}\left(\lambda(\theta), \lambda_{\text {panic }}(\theta)\right)$ is determined on the market, the bank manager best response is:

$$
\begin{aligned}
& \max _{\beta, \mathbb{1}_{\text {conv }}} \frac{e_{1}^{b}}{n_{\max }}=\frac{\left(1-\mathbb{1}_{\text {conv }} \beta\right) E_{1}\left[A \mid f_{L}\right]+\mathbb{1}_{\text {conv }} \beta l-\mathbb{1}_{\text {conv }} C-D}{n_{\max }} \text { s.t. } \\
& R W A_{1}(\theta)=\frac{P_{1}^{m}\left(\lambda(\theta), \lambda_{\text {panic }}(\theta)\right) \cdot n_{\max }}{\left(1-\mathbb{1}_{\text {conv }} \beta\right) \sigma_{A} E_{1}\left[A \mid f_{L}\right]} \geq \tau
\end{aligned}
$$

Liquidation is a form of asset substitution, which allows the bank to diminish the overall value of risk weighted assets, which in turn will increase the $R W A$ ratio. Ceteris paribus, we assume that the bank has a preference towards liquidating assets 
first, as it permits the low trigger CoCo buffer to be used in case of force majeure in the future (in a multi-period model). Another explanation for delaying conversion is high reputational costs for the bank.

If the size of the shock is big enough, and the expected returns are below gains from liquidation $E_{1}\left[A \mid f_{L}\right]<l$ it can readily be seen that the value of equity is maximised if the bank liquidates all risky assets ${ }^{\boldsymbol{}}$. This is a corner solution which brings little insight and so we will not treat this case further.

If $E_{1}\left[A \mid f_{L}\right]>l$, the value of equity is decreasing in the liquidation fraction $\beta$ and increasing in the value of fundamentals $\theta$. Thus the overall costs of bank to maintain $R W A_{1} \geq \tau$ increase as $\lambda_{\text {panic }}(\theta)$ increases, because the bank has to liquidate more of the long-term assets. The bank will maximise the value of equity by minimizing the fraction of risky assets that it has to liquidate. Conditional on liquidation, the share value will be maximised when the constraint will be minimised, and hence binding.

Proposition 1. The bank prefers asset substitution over CoCo conversion, and liquidates a fraction $\beta^{*}\left(\lambda(\theta), \lambda_{\text {panic }}(\theta)\right)$ of long term risky assets as long the proportion of panic investors is below $\lambda_{\text {panic }}^{*}(\theta)$, and otherwise prefers CoCo debt conversion, and further liquidation $\beta_{\text {conv }}^{*}\left(\lambda(\theta), \lambda_{\text {panic }}(\theta)\right)$ if needed.

The banks' best response liquidation fraction of long term risky assets is given by

$$
\beta^{*}\left(\lambda(\theta), \lambda_{\text {panic }}(\theta)\right)=1-\frac{\left[1-\lambda(\theta)-\lambda_{\text {panic }}(\theta)\right] c}{\tau \sigma_{A} e_{0} E\left[A \mid f_{L}\right]\left[\lambda(\theta)+\lambda_{\text {panic }}(\theta)\right]}
$$

The bank's indifference point between asset substitution and CoCo conversion is given by:

$$
\lambda_{\text {panic }}^{*}(\theta)=\frac{c(1-\lambda(\theta))+\lambda(\theta))(B-1) e_{0} \tau \sigma_{A} E\left[A \mid f_{L}\right]}{c-(B-1) e_{0} \tau \sigma_{A} E\left[A \mid f_{L}\right]}
$$

where $B=\underbrace{\frac{E\left[A \mid f_{L}\right]-C-D}{E\left[A \mid f_{L}\right]-l}}_{\text {liquidation }}-\underbrace{\frac{\left(E\left[A \mid f_{L}\right]-D\right)}{\left(E\left[A \mid f_{L}\right]-l\right)(1+\psi C)}}_{\text {conversion }}$.

The derivations can be found in the appendix. Intuitively, the optimal $\lambda_{\text {panic }}^{*}(\theta)$

\footnotetext{
${ }^{6}$ If the bank could further shift the distribution of returns, a moral hazard problem could arise as banks have incentives to 'gamble' and continue with their long term assets due to limited liability (see Martynova and Perott] (ZIII); Chan and van Wijnbergen (JIII)).
} 
depends on the initial capital structure, and dilution size after conversion. There are three possible cases.

We can eliminate the cases where $\lambda_{\text {panic }}^{*}(\theta)$ is not an interior solution based on economically sensible arguments. Firstly, if the optimal threshold between conversion and liquidation $\lambda_{\text {panic }}^{*}(\theta)$ has a negative value, then liquidating all assets always yields a lower value than CoCo conversion. In this case, bank converts first and share value always increases if conversion occurs. This case can happen if CoCos are principal write-down. Otherwise, if $\lambda_{\text {panic }}^{*}(\theta)>1-\lambda(\theta)$, then liquidating all assets is always preferred to CoCo conversion. An interpretation could be that dilution is so large for shareholders, that conversion becomes a solution of last resort. This can be interpreted as CoCos having a very large dilution size $\psi$ for existing shareholders.

The interior solution $\lambda_{\text {panic }}^{*}(\theta) \in\left[0,1-\lambda_{\text {panic }}(\theta)\right]$ guarantees that the bank liquidates first, and converts if $\lambda_{\text {panic }}(\theta)>\lambda_{\text {panic }}^{*}(\theta)$. In this case, the trade-off between dilution and costly liquidation depends on market price of shares, and dilution size $\psi$. After conversion, if the ratio still falls below $\tau_{L}$ bank manager liquidates

$$
\beta_{\text {conv }}^{*}=1-\frac{P_{1}^{m}\left(\lambda(\theta), \lambda_{\text {panic }}(\theta)\right)[1+\psi C]}{\tau \sigma_{A} E\left[A \mid f_{L}\right]}
$$

Let $\bar{\psi}$ be the "neutral conversion" at which there is a zero wealth transfer from CoCo holders to equity holders (Chan and van Wijnbergen, 2017). For $\psi_{L}<\bar{\psi}_{L}$ shareholders benefit from conversion, and for $\psi_{L}>\bar{\psi}_{L}$ the wealth transfer from CoCo holders to equity is negative.

The neutral conversion, with a zero wealth transfer between low trigger CoCo holders to equity holders is

$$
\bar{\psi}_{L}=\frac{\left(\beta^{*}-\beta_{c o n v}^{*}\right)\left(E\left[A \mid f_{L}\right]-l\right)-C}{C\left(1-\beta_{1}^{*}\right) E\left[A \mid f_{L}\right]+\beta^{*} l-C-D}
$$

A derivation of the parameter can be found in the appendix. The existence of an interior solution, where the bank prefers first to do asset substitution depends on the maximum available cash in the market, and the size of the shock to assets. Intuitively, if there is more cash available, equity will trade at fundamental value. Alternatively, if returns are high enough in expectation, there is no need to liquidate any assets to begin with. The proof and full solution of the following proposition can be found in the Appendix. 
Figure 4: Investors decision to sell and fundamentals

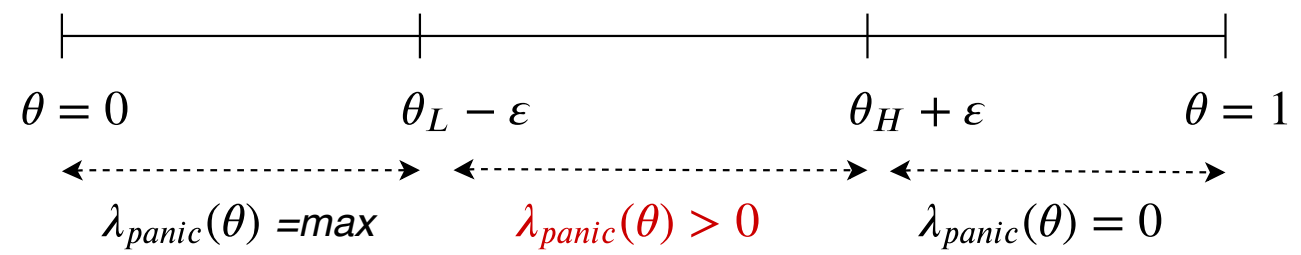

Proposition 2. The bank's best response to liquidate fraction $\beta^{*}(\lambda(\theta))$ is an interior solution $^{\mathbf{\square}}$, up to a maximum amount of cash in the market $\left(1-\lambda(\theta)-\lambda_{\text {panic }}(\theta)\right)$, and a maximum value of expected returns $E\left[A \mid f_{L}\right]$.

\subsubsection{Investors' behavior}

The investors which are not hit by a liquidity shock decide whether to sell or not based on their expected payoffs. If they expect that waiting yields a higher payoff compared to selling equity at current market price, then they will not sell. The bank best responds to the decision of equity holders. If the fundamentals are good enough, and so $\theta>\theta_{H}+\varepsilon$, the incentive compatibility constraint of equity holders to wait until $t=3$ is always met, and the shares trade at fundamental price. The number of equity holders not hit by a liquidity shock that sell in equilibrium is $\lambda_{\text {panic }}(\theta)=0$.

If the fundamentals are bad enough, and so $\theta<\theta_{L}-\varepsilon$, equity holders will sell regardless of the beliefs about the behavior of other equity holders, because conversion is imminent and returns will be very low. Thus, in this region the fraction of late investors who sell is $\lambda_{\text {panic }}(\theta)=1-\lambda(\theta)$. The three regions are summarised in Figure 四.

We build further on the methodology of Goldstein and Pamzner (《III) and we stay close to their notation.

In the intermediate region of fundamentals $\theta_{L}-\varepsilon<\theta<\theta_{H}+\varepsilon$, the expected payoffs for each share are summarised in Table $\boldsymbol{\nabla}$, where $\beta^{*}, \beta_{\text {conv }}^{*}$ are the bank's best response functions derived earlier.

Following Goldstein and Pamzner (지․), we denote by $v\left(\lambda_{\text {panic }}(\theta)\right):(0,1-$

${ }^{7}$ defined as $0<\beta^{*}\left(\lambda_{\text {panic }}(\theta)\right)<10<\lambda_{\text {panic }}^{*}(\theta)<1-\lambda(\theta)$ 
Table 2: Investors' waiting versus selling payoffs

\begin{tabular}{c|c|c}
\hline Sell in & $t=2$ & $t=3$ \\
\hline$\lambda_{\text {panic }}(\theta)<\lambda_{\text {panic }}^{*}(\theta)$ & $P^{m}\left(\lambda(\theta), \lambda_{\text {panic }}(\theta)\right)$ & $d_{2}=\left(1-\beta^{*}\right) E\left[A \mid f_{L}\right]+\beta^{*} l-C-D$ \\
$\lambda_{\text {panic }}(\theta)>\lambda_{\text {panic }}^{*}(\theta)$ & $P^{m}\left(\lambda(\theta), \lambda_{\text {panic }}(\theta)\right)$ & $d_{3}=\frac{\left(1-\beta_{\text {conv }}^{*}\right) E\left[A \mid f_{L}\right]+\beta_{\text {conv }}^{*} l-D}{1+\psi C}$ \\
\hline
\end{tabular}

$\lambda(\theta)) \rightarrow \mathbf{R}$ the function that captures the value of waiting until $t=3$ minus value of selling at $t=2$ for equity holders:

$$
v\left(\lambda_{\text {panic }}(\theta)\right)= \begin{cases}d_{2}\left(\beta^{*}\right)-P_{1}^{m}\left(\lambda_{\text {panic }}(\theta)\right) & \text { if } \lambda_{\text {panic }}(\theta)<\lambda_{\text {panic }}^{*}(\theta) \\ d_{3}\left(\beta_{\text {conv }}^{*}\right)-P_{1}^{m}\left(\lambda_{\text {panic }}(\theta)\right) & \text { otherwise. }\end{cases}
$$

The proofs of unique equilibrium in Morris and Shin (1098); Goldstein and Pallzner (ㅍI.1) relate to how agents interact with each other. The decisions are global strategic complementarities if the incentive to take a specific action is monotonically increasing with the number of agents who take the same action (Goldstein and Pallzner, (2011.). In contrast, strategic substitutes are when the action incentives of an agent are monotonically decreasing with the number of agents who take that decision.

Depending on the initial capital and CoCo design, there can be one, multiple or no indifference points in investors' value of waiting minus value of selling: $v(\lambda(\theta))=0$. More precisely, if it is always better to wait, so $v\left(\lambda_{\text {panic }}(\theta)\right)>0 \forall \lambda_{\text {panic }}(\theta) \in[0,1-$ $\lambda(\theta)$ ], then in equilibrium $\lambda_{\text {panic }}(\theta)=0$, as all late investors prefer to wait. Multiple equilibria arise if $\exists$ at least $\lambda_{11}(\theta), \lambda_{12}(\theta) \in[0,1-\lambda(\theta)], \quad \lambda_{11}(\theta) \neq \lambda_{12}(\theta)$ such that $v\left(\lambda_{11}(\theta)\right)=v\left(\lambda_{12}(\theta)\right)=0$. We guarantee a unique equilibrium if $\exists^{*} \lambda_{\text {panic }}(\theta) \in$ $(0,1-\lambda(\theta))$ s.t. $v\left(\lambda_{\text {panic }}(\theta)\right)=0$. We further assume a capital structure that allows for a unique equilibrium. Our model does not allow for closed form solutions, but we are able to provide numerical solutions or confidence intervals which have only a single crossing.

Lemma 1. For dilutive $\operatorname{Co} \operatorname{Cos} \psi>\bar{\psi}$, the necessary and sufficient condition for late investor decisions to be strategic complementarities is that $v\left(\lambda_{\text {panic }}(\theta)\right)$ is piecewise monotonically decreasing on the intervals $\left(0, \lambda_{\text {panic }}^{*}(\theta)\right)$ and $\left[\lambda_{\text {panic }}^{*}(\theta), 1-\lambda(\theta)\right)$

Condition under lemma $\mathbf{\square}$ is achieved as long as the fraction $1-\tau_{L}$ of expected 
returns on long term assets is larger than the liquidation value: $l<E_{1}\left[A \mid f_{L}\right](1-\tau)$.

We further proceed to derive the unique equilibrium threshold $\theta^{*}$ above which all agents with a signal $\theta_{i}>\theta^{*}$ decide to wait for payoff payments at $t=2$ and sell if $\theta_{i}<\theta^{*}$. Following the uniqueness proof of Goldstein and Pallznen (खण1). $)$, a unique $\theta^{*}$ exists if $v\left(\lambda_{\text {panic }}(\theta)\right)$ crosses zero only once. Due to the discontinuity of $v\left(\lambda_{\text {panic }}(\theta)\right)$ point $\lambda^{*}(\theta)$, we cannot apply one-to-one their methodology, and we state additional restrictions on the capital structure of the bank to guarantee uniqueness. As a consequence, we can argue that under specific initial capital structures the model can have multiplicity of fire sales of equity equilibria, or none.

Figure 5: Single crossing cases

I. Single crossing before conversion

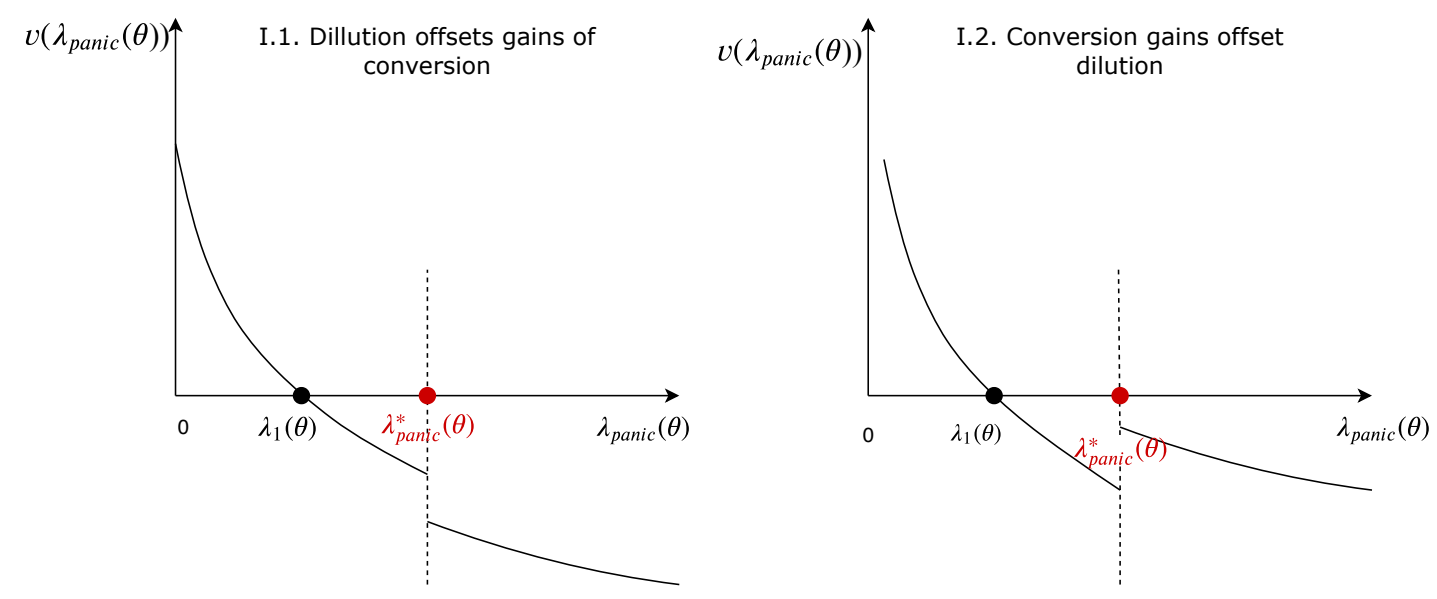

II. Single crossing after conversion
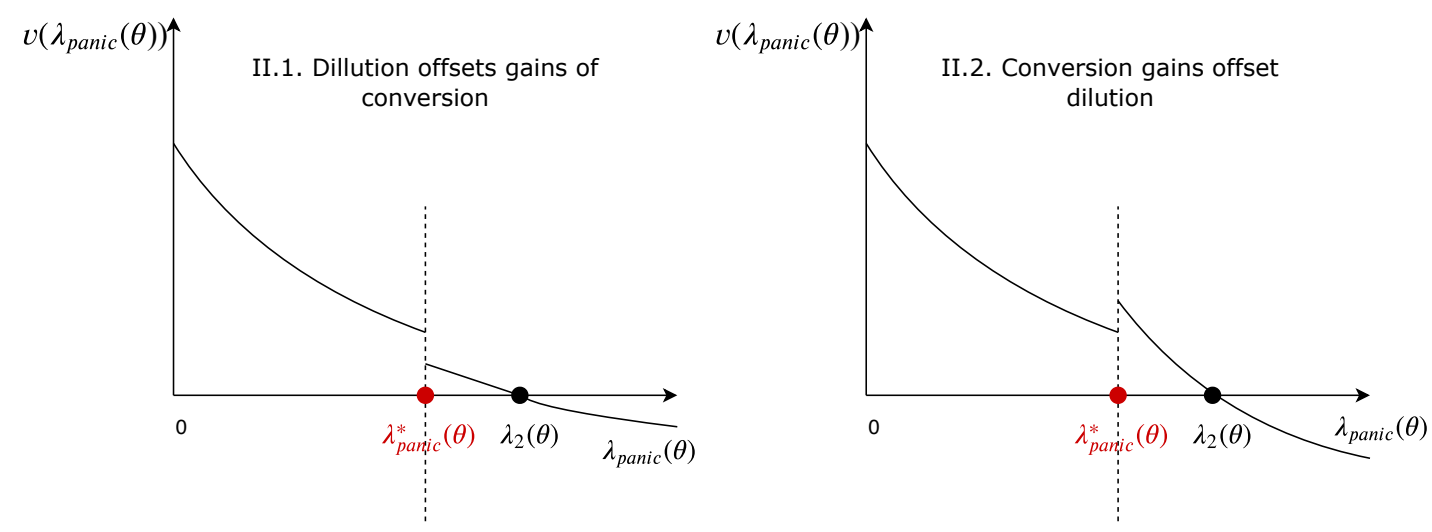
Table 3: Indifference points between waiting and selling for investors

\begin{tabular}{l|l|l}
\hline & $\lambda_{2}(\theta)-\lambda_{\text {panic }}^{*}(\theta) \geq 0$ & $\lambda_{2}(\theta)-\lambda_{\text {panic }}^{*}(\theta)<0$ \\
\hline$\lambda_{1}(\theta)-\lambda_{\text {panic }}^{*}(\theta) \geq 0$ & Single crossing after conversion & No crossing \\
$\lambda_{1}(\theta)-\lambda_{\text {panic }}^{*}(\theta)<0$ & Double crossing & Single crossing before conversion \\
\hline
\end{tabular}

Figure displays the four possible cases of single crossing: before (I), or after conversion (II), which further depend on whether dilution offsets gains of conversion (I.1 and II.1) or not(I.2 and II.2). Yet again, the relationship will be uniquely determined by the parameters of the initial capital structure, and how the conversion rate of $\psi$ compares to the "neutral conversion" $\bar{\psi}$ from ?. At this stage it is worth noting that for the single crossing the dilutive power of CoCos does not matter. Intuitively, in cases I.1 and I.2 from figure $\mathbf{\square}$, even under the most optimistic scenario (I.2) the dilution gains cannot offset the losses from the decrease in current market price. Additionally, if the single crossing happens after conversion, then the dilution vs. conversion gains will only swift $\lambda_{2}(\theta)$ : in II.1 the indifference point will be achieved for a lower $\lambda_{\text {panic }}$ than under II.2. Hence we do not distinguish further between $I .1 \wedge I .2$ and $I I .1 \wedge I I .2$ as we argue that it does not bring any additional economic insight.

Let $\lambda_{1}(\theta)$ be the solution of: $d_{2}(\theta)-P^{m}=0$ and $\lambda_{2}(\theta)$ the value which solves: $d_{3}(\theta)-P^{m}=0$. In other words, $\lambda_{1}(\theta), \lambda_{2}(\theta)$ are the threshold values at which equity holders are indifferent between selling or waiting before, or after conversion respectively.

Proposition 3. The necessary and sufficient conditions for the existence of a unique point at which equity holders are indifferent between waiting until $t=2$ or selling their equity are:

(i) before conversion -

$$
\left\{\begin{array}{l}
0<\lambda_{1}(\theta) \leq \lambda_{\text {panic }}^{*}(\theta) \\
0<\lambda_{2}(\theta)<\lambda_{\text {panic }}^{*}(\theta)
\end{array}\right.
$$

(ii) after conversion -

$$
\left\{\begin{array}{l}
\lambda_{1}(\theta)>\lambda_{\text {panic }}^{*}(\theta) \\
\lambda_{2}(\theta) \geq \lambda_{\text {panic }}^{*}(\theta)
\end{array}\right.
$$


Intuitively, these conditions capture a simultaneity issue: the indifference condition $v\left(\lambda_{\text {panic }}(\theta)\right)=0$ has to co-exist in the same variable space as the bank's best response. We construct a proof by contradiction in the Appendix.

\section{Lower and upper dominance regions}

Outside the intermediate region, there is a range of extremely good or extremely bad fundamentals, where the behavior of equity holders is independent on the others decision.

We guarantee that the lower dominance region is nonempty if $\theta_{L}>2 \varepsilon$. The lower bound for $\theta_{L}$ is established if even for the lowest possible returns today, the equity holder is not willing to wait for payoffs: $P^{m}\left(\theta_{L}\right) \geq d_{2}\left(\theta_{L}\right)$. The lowest possible market price is obtained if all equity holders sell: $\lambda_{\text {panic }}(\theta)=1-\lambda(\theta)$. A complete proof can be found in the Appendix.

The condition for a non-empty lower dominance region is implicitly defined from the following inequality, which can be trivially solved for any monotonically increasing functional form of $F_{R_{L}}($.$) :$

$$
F\left(\theta_{L}-\varepsilon\right)-F\left(\theta_{L}+\varepsilon\right)=D>0
$$

Let $\theta_{U} \leq \theta_{H}$ be the upper bound of fundamentals, above which the expected utility of waiting for residual payments is always at least as large as the expected utility of selling equity at $t=1$, regardless of how many shares are traded in the market. This condition is trivially satisfied, due to our earlier assumption that for $\theta>\theta_{H}+\varepsilon$ shares trade at fundamental value, independent on how many shares are sold. In the upper dominance region $R W A\left(\theta \mid f_{L}\right) \geq R W A\left(\theta_{H} \mid f_{L}\right)>\tau_{H}$ fundamentals are strong enough that the bank will be able to pay back the debt without further asset substitution or conversion and the equity holders will make a positive profit at $t=3$.

Corollary 2. A late investor always sells if she observes a signal $\theta_{i} \leq \theta_{L}-\varepsilon$. A late investor never sells if she observes a signal $\theta_{i} \geq \theta_{U}+\varepsilon$.

When $\theta<\theta_{L}-2 \varepsilon$, all agents are guaranteed to obtain a signal $\theta_{i}<\theta_{L}-\varepsilon$, and thus all equity holders sell their shares at $t=2: \lambda^{*}(\theta)=1-\lambda(\theta)$, independent 
on the actions of others. Symmetrically, for $\theta>\theta_{H}+2 \varepsilon$, all agents obtain a signal $\theta_{i}>\theta_{H}+\varepsilon$ and thus no equity holder sells at $t=2$.

The distribution of $\varepsilon$ is uniform over $[0,1]$ and in the interval $\left[\theta_{L}-2 \varepsilon, \theta_{L}\right]$ the fraction of equity holders which observe signals below $\theta_{L}-\varepsilon$ decreases linearly at a rate of $\frac{1}{2 \varepsilon}$ - see Figure $\mathbf{b}$. Similarly, in the region $\left[\theta_{U}, \theta_{U}+2 \varepsilon\right]$, the proportion of agents who receive signals $\theta_{i}>\theta_{U}+\varepsilon$ increases at rate $\frac{1}{2 \varepsilon}$. Figure $\mathbf{b}$ follows the same format of Gnddstein and Pauner (2011.5). The solid line represents the upper bound from the upper dominance region: the maximum number of equity holders that sell. The dotted line denotes the lower bound of equity holders which sell. On the intervals $\left[0, \theta_{L}-2 \varepsilon\right]$ and $\left[\theta_{U}+2 \varepsilon, 1\right]$, the segments fully overlap.

Figure 6: Proportion of equity holders that sell

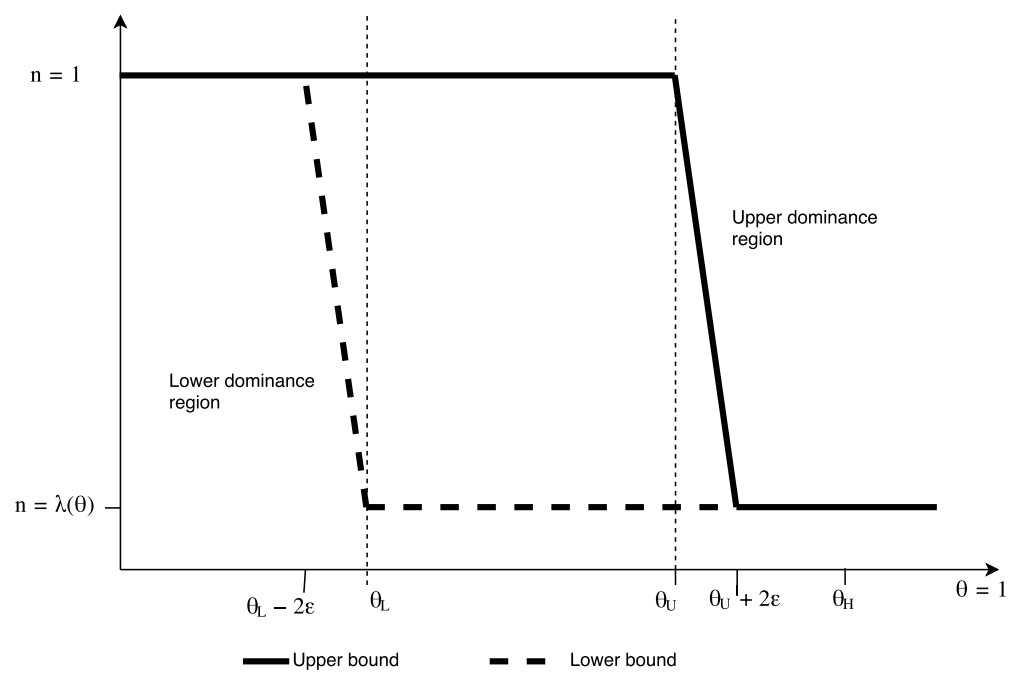

\subsubsection{Unique equilibrium}

Theorem 2. Under single crossing conditions for $v\left(\lambda_{\text {panic }}(\theta)\right)=0$, there is a unique equilibrium $\theta^{*}$ below which a late investor with signal $\theta_{i}<\theta^{*}$ sells all her shares at $t=2$, and otherwise waits for residual payments at $t=3$.

A sketch of the proof based on Goldstein and Pawner (खा1!) is presented in the Appendix. Their proof uses the continuity property of $v\left(\lambda_{\text {panic }}(\theta)\right)$, which does not generally hold in our case. We can prove that the unique equilibrium exists if $v\left(\lambda_{\text {panic }}(\theta)\right)=0$ only once.

\footnotetext{
${ }^{8}$ Which is derived from the corresponding probability density function.
} 
The equilibrium value $\theta^{*}$ is defined such that an equity holder with signal $\theta^{*}$ is indifferent between selling at $t=2$ or waiting for dividend payments over all possible values of $\lambda_{\text {panic }}\left(\theta^{*}\right)$. The threshold $\theta^{*}$ is implicitly defined from:

$$
\int_{0}^{\lambda^{*}\left(\theta^{*}\right)}\left(d_{2}\left(\theta^{*}\right)-P^{m}\left(\lambda_{\text {panic }}\left(\theta^{*}\right)\right) d \lambda_{\text {panic }}+\int_{\lambda_{1}^{*}\left(\theta^{*}\right)}^{1-\lambda(\theta)}\left(d_{3}\left(\theta^{*}\right)-P^{m}\left(\lambda_{\text {panic }}\left(\theta^{*}\right)\right)\right) d \lambda_{\text {panic }}=0\right.
$$

Corollary 3. The proportion of total equity holders that sell, as a function of fundamentals is given by:

$$
n\left(\theta, \theta^{*}\right)= \begin{cases}1 & \theta<\theta^{*}-\varepsilon \\ \lambda(\theta)+(1-\lambda(\theta)) \frac{\theta^{*}-\theta+\varepsilon}{2 \varepsilon} & \theta^{*}-\varepsilon \leq \theta \leq \theta^{*}+\varepsilon \\ \lambda(\theta) & \theta>\theta^{*}+\varepsilon\end{cases}
$$

Goldstein and Pamznen (2010) call the corresponding intermediate region from Figure $\mathbf{6}$ : $\theta \in\left(\theta_{L}-2 \varepsilon, \theta_{U}+2 \varepsilon\right)$ as the panic based runs region. In our model this is the critical region which leads to multiple inefficiencies.

In case of uniformly distributed errors, the proportion of equity which sell in equilibrium is depicted in Figure $\mathbf{\square}$.

\section{Figure 7}

\section{Proportion of investors which sell at $\mathrm{t}=1$}

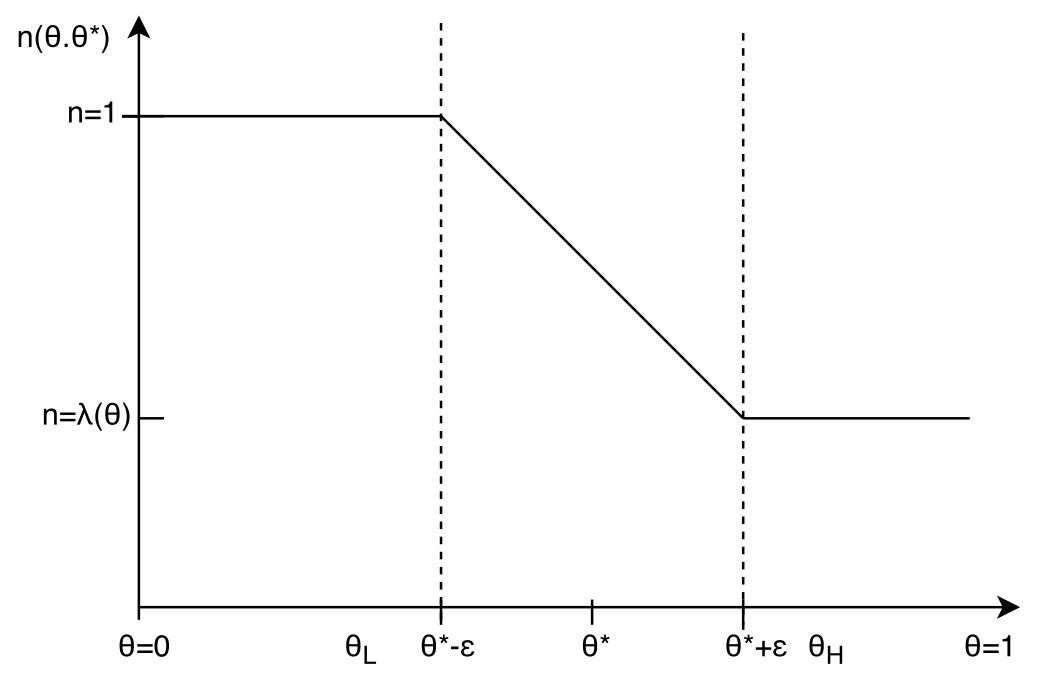


if $\lambda_{\text {panic }}(\theta)$ is high enough, the bank converts when in fact the book value of $R W A>\tau$. This conversion is inefficient for CoCo holders, and the effect is ambiguous for equity holders. If dilution offsets the gains of conversion, then it has a negative effect for equity holders. Otherwise, if $\lambda_{\text {panic }}(\theta)<\lambda_{\text {panic }}^{*}(\theta)$ then it leads to inefficient asset substitution which decreases overall payoffs, which is harmful for existing equity holders.

If CoCos are non-dilutive $\psi_{L}<\bar{\psi}_{L}$, then the decisions to sell of late investors are strategic substitutes. In this case, the CoCos are not artificially triggered, as long as shareholders cannot sort sell their equity. The possibility of re-purchasing, combined with limited cash in the market pricing, CoCos with dilution $\psi_{L}<\bar{\psi}_{L}$ are not a good loss absorption mechanism, as it creates incentives for shareholders to force CoCo conversion by short-selling their equity. Note that an extreme case of non-dilution is given by principal write-down CoCos.

Proposition 4. Under the assumption that equity holders cannot re-buy their shares and CoCos are non-dilutive $\psi_{L}<\bar{\psi}_{L}$, the threshold equilibrium $\theta_{n d}^{*}$ below which all equity holders sell is $\theta_{n d}^{*}=\theta_{L}-\varepsilon$. The number of equity holders who sell as a function of fundamentals is:

$$
n_{n d}\left(\theta, \theta^{*}\right)= \begin{cases}1 & \theta \leq \theta^{*}-\varepsilon \\ \frac{\theta^{*}-\theta+\varepsilon}{2 \varepsilon} & \theta^{*}-\varepsilon<\theta<\theta^{*}+\varepsilon \\ 0 & \theta>\theta^{*}+\varepsilon\end{cases}
$$

\section{Two CoCo buffers model and analysis}

\subsection{Model differences compared to baseline model}

In this case, the bank has two CoCo buffers compared to the baseline model - see timeline with changes in red compared to the baseline in Figure $\mathbf{\theta}$. The bank raises a total amount of outstanding CoCo debt $C_{H}$, with a trigger level $\tau_{H}$, and a conversion ratio $\psi_{H}$, and $C_{L}$ CoCo debt, with trigger level $\tau_{L}$, and ratio $\psi_{L}$. By construction, $\tau_{H}>\tau_{L}$. In this case, total equity amounts to $e_{0}=A-D-C_{H}-C_{L}$.

The bank has to comply with the capital requirement in both time periods $t=1$ and $t=2$. We assume that the shock to the expected asset returns is high enough such that the $R W A_{1}$ falls below the high CoCo trigger $\tau_{H}$, but it is higher than the 
Table 4: Initial balance sheet two CoCo buffers model

\begin{tabular}{l|l}
\hline Assets & Liabilities \\
\hline A - initial investment & $\mathrm{D}$-senior debt \\
& $C_{H}-$ high trigger CoCo \\
& $C_{L}-$ low trigger CoCo \\
& $e_{0}-$ initial equity \\
\hline
\end{tabular}

low trigger $\tau_{L}$ :

$$
\tau_{L}<R W A_{1}=\frac{E_{1}\left[A \mid \tau_{L}\right]-D-C_{L}-C_{H}}{\sigma_{A} E_{1}\left[A \mid f_{L}\right]}<\tau_{H}
$$

After the manager incorporates the shock, the bank has to decide between asset substitution or high CoCo conversion. The trade-off is between lower returns at $t=3$ versus possible fire sales of equity at $t=2$. CoCo conversion signals to the market that returns are lower than initially expected which subsequently influence the behaviour of equity holders at $t=2$. We denote by $\theta_{H} \in(0,1)$ the corresponding values of fundamentals such that conditional on a high CoCo initial conversion, at $t=1$ is:

$$
R W A_{1}\left(\theta_{H} \mid f_{L}\right)=\frac{e_{1}^{b}}{\sigma_{A} \int_{\theta-\varepsilon}^{\theta+\varepsilon} A f_{R_{L}}(\theta) \theta d \theta}>\tau_{L}
$$

Figure 8: Timeline two CoCo buffers

$$
\begin{aligned}
& t=1 \quad t=2 \quad t=3 \\
& \begin{array}{|l|l|l} 
& & \\
\hline \text { 1. Shock to asset returns. } & \text { 1. Agents obtain noisy signal of fundamentals } \theta . & \begin{array}{l}
\text { 1. Realisation of returns, } \\
\text { debt and dividend repayments. }
\end{array}
\end{array} \\
& \text { 2. Bank converts high } \\
& \text { CoCo debt or does asset 3. (Potential) fire-sales of equity. }
\end{aligned}
$$

The bank manager decision at $t=1$ is similar now to the one at $t=2$. We summarise the extended decision tree in Figure $\mathbf{q}$. The key difference compared to the baseline model is that, depending on the high CoCo design features, the bank manager might have incentives to prevent the high CoCo conversion via initial asset 
substitution.

Figure 9: Bank manager decision tree

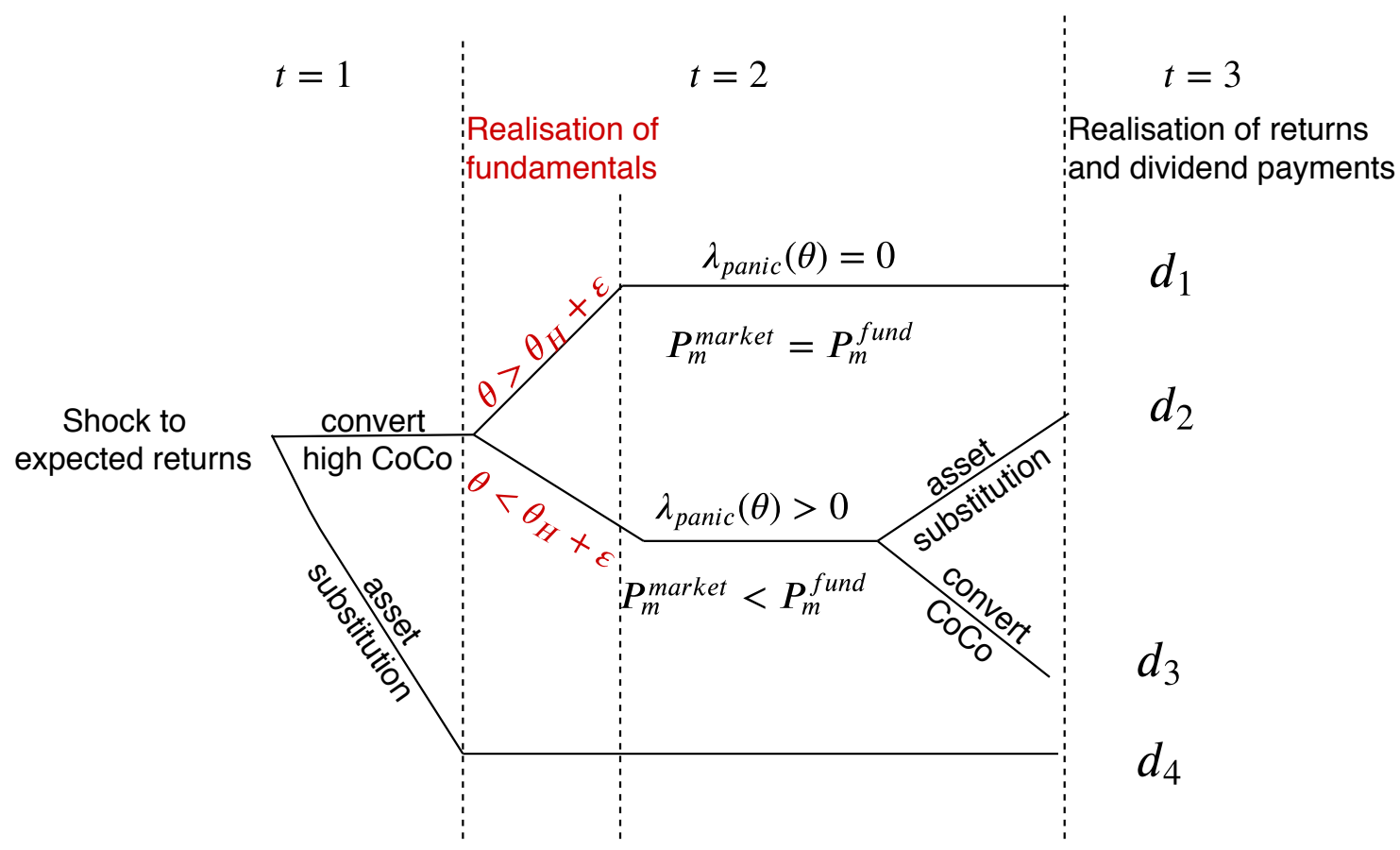

The market clearing price at $t=2$ is determined in the same way as before, with the difference that the maximum number of shares in the market changes now to:

$$
n_{\text {max }}(\theta)= \begin{cases}1 & \text { if no conversion } \\ 1+\psi_{H} C_{H} & \text { if high CoCo converts } \\ 1+\psi_{H} C_{H}+\psi_{L} C_{L} & \text { if both CoCos convert }\end{cases}
$$

\subsection{Equilibrium analysis}

We solve for equilibrium using backward induction, but unlike the baseline model, now the bank has to take an additional decision at $t=1$ which is whether to convert the high CoCo or do asset substitution instead - see Figure $\mathbf{q}$. Moreover, we further distinguish between the case where the ratio is evaluated at market value, and the case when the market capitalisation is book based, as it is done in practice. 


\subsubsection{Market based trigger}

Decision at $t=2$

In this case the capitalisation ratio $R W A_{2}$ is evaluated in the market. The decision of the bank manager and investors' behaviour is identical with the baseline case.

In case the bank converted the high CoCo at $t=1$, the bank's best response liquidation fraction changes compared to the benchmark case. Now, the indifference point between conversion of the low trigger CoCo and asset liquidation is given by:

$$
\lambda_{\text {panic }}^{*}(\theta)=\frac{c(1-\lambda(\theta))+\lambda(\theta)(G-1) e_{0} \tau_{L} E\left[G \mid f_{L}\right]}{c-(G-1) e_{0} \tau_{L} E\left[G \mid f_{L}\right]}
$$

where $G=\frac{E\left[A \mid f_{L}\right]-C_{L}-B}{E\left[A \mid f_{L}\right]-l}-\frac{\left(E\left[A \mid f_{L}\right]-B\right)\left(1+\psi_{H} C_{H}\right)}{\left(E\left[A \mid f_{L}\right]-l\right)\left(1+\psi_{H} C_{H}+\psi_{L} C_{L}\right)}$.

The proof can be found in the appendix.

We previously defined $\overline{\psi_{L}}$ as the zero wealth transfer point between equity holders and CoCo holders. The neutral conversion in this case incorporates the previous high CoCo conversion.

Corollary 4. The neutral conversion, with a zero wealth transfer between low trigger Co Co holders to equity holders is

$$
{\overline{\psi_{L}}}_{L}=\frac{\left(\beta_{1}^{*}-\beta_{1, C}^{*}\right)\left(E\left[A \mid f_{L}\right]-l\right)-C_{L} \cdot\left(1+\psi_{H} C_{H}\right)}{C_{L}\left(1-\beta_{1}^{*}\right) E\left[A \mid f_{L}\right]+\beta_{1}^{*} l-C_{L}-D}
$$

A derivation of the parameter can be found in the appendix. We compare how the CoCo structure depends on optimal liquidation and conversion, and we find the following intuitive results. More cash is available in the market leads to a lower

optimal liquidation fraction, as equity is traded closer to the fundamental value $\left(\frac{\partial \beta_{1}^{*}}{\partial c}<\right.$ $0)$. The size of the shock is inversely proportional with the optimal size of liquidation. The bank manager is more likely to convert the CoCo debt faster if the trigger is higher.

Corollary 5. If $\theta<\theta_{H}+\varepsilon$ and the long term risky asset faces a negative shock to returns at $t=1$, then the optimal fraction of asset substitution $\beta_{1}^{*}$ at $t=2$ depends in the following way on the CoCo structure: 
(i) If the high CoCo debt was highly dilutive for existing shareholders, then there is less need for other forms of recapitalisation at a later stage $\left(\frac{\partial \beta_{1}^{*}}{\partial \psi_{H}}<0\right)$

(ii) The bank manager postpones conversion as the size of expected dilution increases $\left(\frac{\partial \lambda_{\text {panic }}^{*}}{\partial \psi_{L}}>0\right)$.

(iii) Wealth transfer and conversion

- If the low CoCo debt is non-dilutive for existing shareholders, then the bank manager prefers conversion over asset liquidation, and this decision is increasing with the size of CoCo debt $C_{L}\left(\frac{\partial \lambda_{\text {panic }}^{*}}{\partial C_{L}}<0\right)$.

- If the CoCo debt is dilutive, then the bank postpones conversion, and opts for asset substitution instead.

\subsubsection{Investors' behavior}

In a similar manner with the baseline model, the investors decide between selling and waiting. Compared to the first case, now the pay-off structure is different, which in turn might change their decisions. The crucial difference is the increase in the number of shares after the first conversion, but the functions only change by a scalar, making the function of waiting or selling shift by a scalar, and the solution method equivalent with the baseline case. In this case, the value function that investors face, based on the payoffs in Table $\boldsymbol{日}$.

$$
v\left(\lambda_{\text {panic }}(\theta)\right)= \begin{cases}d_{2}\left(\beta_{2}^{*}\right)-P_{2}^{m}\left(\lambda_{\text {panic }}(\theta)\right) & \text { if } \lambda_{\text {panic }}(\theta)<\lambda_{\text {panic }}^{*}(\theta) \\ d_{3}\left(\beta_{2, \text { conv }}^{*}\right)-P_{2}^{m}\left(\lambda_{\text {panic }}(\theta)\right) & \lambda_{\text {panic }}(\theta) \geq \lambda_{\text {panic }}^{*}(\theta)\end{cases}
$$

Table 5: Investors' waiting versus selling payoffs after first CoCo conversion

\begin{tabular}{c|c|c}
\hline Sell in & $t=2$ & $t=3$ \\
\hline$\lambda_{\text {panic }}(\theta)<\lambda_{\text {panic }}^{*}(\theta)$ & $P^{m}\left(\lambda(\theta), \lambda_{\text {panic }}(\theta)\right)$ & $d_{2}=\frac{\left(1-\beta_{2}^{*}\right) E\left[A \mid f_{L}\right]+\beta_{2}^{*} l-C-D}{1+\psi_{H} C_{H}}$ \\
$\lambda_{\text {panic }}(\theta)>\lambda_{\text {panic }}^{*}(\theta)$ & $P^{m}\left(\lambda(\theta), \lambda_{\text {panic }}(\theta)\right)$ & $d_{3}=\frac{\left(1-\beta_{2, \text { conv }}^{*}\right) E\left[A \mid f_{L}\right]+\beta_{2, \text { conv }}^{*} l-D}{1+\psi_{H} C+H+\psi_{L} C_{L}}$ \\
\hline
\end{tabular}

Based on this function specification, there is a unique $\theta^{*}$, below which investors with signal $\theta_{i}<\theta^{*}$ sell their equity, and otherwise wait for residual payments. This 
result is formalised under Theorem $\boldsymbol{\nabla}$. The threshold equilibrium $\theta^{*}$ is determined implicitly by:

$$
\begin{gathered}
\int_{\lambda_{\text {panic }}\left(\theta^{*}\right)=0}^{\lambda_{\text {panic }}\left(\theta^{*}\right)=\lambda^{*}\left(\theta^{*}\right)}\left(d_{1}\left(\theta^{*}\right)-P_{2}^{m}\left(\lambda_{\text {panic }}\left(\theta^{*}\right)\right) d \lambda_{\text {panic }}+\right. \\
+\int_{\lambda_{\text {panic }}\left(\theta^{*}\right)=\lambda^{*}\left(\theta^{*}\right)}^{1-\lambda(\theta)}\left(d_{2}\left(\theta^{*}\right)-P_{2}^{m}\left(\lambda_{\text {panic }}\left(\theta^{*}\right)\right)\right) d \lambda_{\text {panic }}=0
\end{gathered}
$$

Compared to the benchmark case, the threshold $\lambda^{*}(\theta)$ is either larger or smaller depending on the conversion ratio $\psi_{H}$, and the size of CoCo debt $C_{H}$.

To summarise, in case of high CoCo conversion at $t=0$, the equilibrium expected dividend payments at $t=1$ are given by:

$$
\begin{aligned}
& d_{1}(\theta)=\frac{E\left[A \mid f_{L}\right]-C_{L}-B}{1+\psi_{H} C_{H}} \text { if } \theta>\theta_{H}+\varepsilon \\
& d_{2}(\theta)=\frac{\left(1-\beta_{1}^{*}\right) E\left[A \mid f_{L}\right]+\beta_{1}^{*} l-C_{L}-B}{1+\psi_{H} C_{H}} \text { if } \theta_{H}+\varepsilon>\theta>\theta^{*} \\
& d_{3}(\theta)=\frac{\left(1-\beta_{1, \text { conv }}^{*}\right) E\left[A \mid f_{L}\right]+\beta_{1, \text { conv }}^{*} l-B}{1+\psi_{H} C_{H}+\psi_{L} C_{L}} \text { if } \theta^{*}>\theta>\theta_{L}-\varepsilon \\
& d_{4}(\theta)=0 \text { if } \theta<\theta_{L}-\varepsilon
\end{aligned}
$$

\section{Decision at $t=2$ in case of initial asset substitution}

Insofar we treated the case where the high trigger CoCo has been converted at $t=1$, which signaled to the market bad asset quality, which in turn led to inefficient conversion. In case of initial asset substitution at $t=1$, now there are two CoCos which can convert. We assume that unlike CoCo conversion, asset substitution is not perceived as such as a strong signal by the market. This is in line with the industry observation of the coupon payment interruption on CoCo debt by Deutsche bank in 2016, which led to strong negative market reactions.

There will be no panic based agents who intend to sell, and so $\lambda_{\text {panic }}(\theta)=0$. This simplifying assumption does not chance the key results, but rather provides a more intuitive perspective on the trade-off between asset substitution and conversion. Nonetheless, this asset substitution is in place before the market and the bank has any signal regarding the state of fundamentals.

Corollary 6. Regardless of the state of fundamentals, there is never a need for CoCo conversion or further asset substitution at $t=1$ if the bank manager liquidates at 
$t=0$ a minimum of:

$$
\beta_{1}^{*}=\frac{C_{H}+C_{L}+D-\delta\left(1-\tau_{H}\right)}{l-\delta\left(1-\tau_{H}\right)}
$$

where $\delta$ is an infinitesimally positive value, close to 0.

In the case where the bank tries to self-insure against conversion, by the large asset substitution towards safe assets described in Corollary $\mathbf{0}$, then the dividend payments are lower in expectation compared to an initial conversion of the high trigger CoCo.

\section{Bank manager decision at $t=1$}

Once the shock to asset returns is observed by the bank manager, they will have to report the value of risk weighted assets and the risk weighted capital requirement. The trade-off that he faces is between reporting truthfully, which leads to immediate conversion of the high CoCo $R W A_{1}<\tau_{H}$, or engaging in asset substitution which will lead to a higher RWA ratio, due to the decrease in the riskiness of asset portfolio.

The bank manager must liquidate a minimum fraction of $\beta_{1}$, described by:

$$
\beta_{1}=\frac{E\left[A \mid f_{L}\right]\left(1-\tau_{H}\right)-C_{L}-D-C_{H}}{E\left[A \mid f_{L}\right]\left(1-\tau_{H}\right)-l}
$$

such that the risk based capital ratio is above $\tau_{H}$ :

$$
R W A_{1}=\frac{\left(1-\beta_{2}\right) E\left[A \mid f_{L}\right]+\beta_{1} l-C_{L}-C_{H}-D}{\left.\left(1-\beta_{0}\right)\right) E\left[A \mid f_{L}\right]}>\tau_{H}
$$

This insures that at $t=2$ only fraction $\lambda(\theta)$ of investors sell and there are no panicked agents in the market: $\lambda_{\text {panic }}(\theta)=0$. For this value of $\beta_{1}$, the value of fundamentals at $t=2$ can lead to further CoCo conversion but shares will still be traded at fundamental value.

To further restrict the case space at $t=2$ we assume a liquidation of $\beta_{1}^{*}$, as described in Corollary $\mathbf{G}^{\mathbf{q}}$.

\footnotetext{
${ }^{9}$ For completeness we should re-derive the cases for conversion $R W A_{1}>\tau_{H} ; \tau_{L}<R W A_{1}<$ $\tau_{H} ; R W A_{1}<\tau_{L}$ and calculate dividend payments. Nonetheless, the key intuition and results for this paper will not change, so we abstract from this matter and keep it in a simpler format.
} 
In case of initial asset substitution, expected dividends at $t=3$ are:

$$
d_{4}(\theta)=\left(1-\beta_{1}^{*}\right) E\left[A \mid f_{L}\right]+\beta_{1}^{*} l-C_{L}-C_{H}-D \quad \forall \theta \in(0,1]
$$

At $t=1$, the overall expected dividend payments in case of conversion is:

$$
\begin{aligned}
e_{1}^{\mathrm{conv}=} & \int_{\theta_{H}+\varepsilon}^{1} \operatorname{Pr}\left(\theta>\theta_{H}+\varepsilon\right) d_{0}(\theta) d \theta+\int_{\theta^{*}}^{\theta_{H}+\varepsilon} \operatorname{Pr}\left(\theta^{*}<\theta<\theta_{H}+\varepsilon\right) d_{1}(\theta) d \theta+ \\
& \int_{\theta_{L}-\varepsilon}^{\theta^{*}} \operatorname{Pr}\left(\theta_{L}-\varepsilon<\theta<\theta^{*}\right) d_{2}(\theta) d \theta+\int_{0}^{\theta_{L}-\varepsilon} \operatorname{Pr}\left(\theta<\theta_{L}-\varepsilon\right) d_{3}(\theta) d \theta
\end{aligned}
$$

and in case of asset substitution:

$$
e_{1}^{\text {subst }}=\int_{\theta=0}^{\theta=1} d_{4}(\theta) d \theta
$$

The manager prefers conversion if $e_{0}^{\text {conv }}>e_{0}^{\text {subst }}$. This time, the trade-off is driven by the functional form of expected returns, and the distance between $\theta^{*}$ and $\theta_{H}, \theta_{L}$. The most efficient conversion space from an optimal bail-in perspective is achieved for $\lambda_{\text {panic }}(\theta)=0$, thus if $\theta^{*}=\theta_{L}-\varepsilon$. For a distribution of returns with fat tails, conversion dominates initial asset substitution, due to the limited liability property of the bank. In contrast, for a uniform distribution of returns, we find that the driver of results is $\theta^{*}$ : a lower value of $\theta^{*}$ leads to an increasing value of $e_{0}^{\text {conv }}$.

\subsection{Book value trigger}

The equity holders behavior crucially depends on the type of conversion, as shown in the market case. Nonetheless, the market price behavior is not reflected in the book value CET ratio. Under equal issuance costs, if the bank tries to protect existent equity holders it should issue non-dilutive CoCos.

Although all CoCos issued so far are book-value based, there is very little research

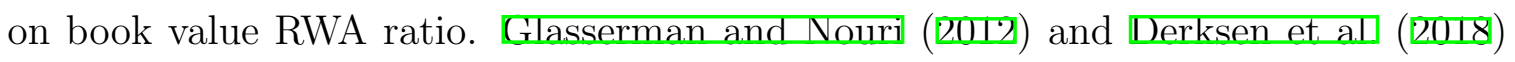
develop a valuation model for CoCos, when the RWA ratio is book based. Due to the lack of existing stylized equations in discrete time of what constitutes the book value of equity, for the scope of this paper we inspire from current regulation. The International Financial Reporting Standard (IFRS) makes a distinction between occurred and expected credit loss. The regulation which was in place until 1st of January 
2018 states that only occurred losses should be incorporated in the balance sheets of banks. Nonetheless, under the new IFRS 9 rules with effect from 2018 firms have to incorporate expected credit loss in their balances (एFRSG, ㅍI4). More precisely, they have to change the accounting value if "the credit risk increases significantly and the resulting credit quality is not considered to be low credit risk" (IFRSG, 20I4). For brevity and consistency with the earlier section, we further incorporate the expected credit loss as expected lower returns in the book value of equity.

Based on existing practice, we define the book value of equity as the (discounted) expected value of long term assets minus liabilities.

\subsubsection{Occurred credit loss}

In this case, $R W A_{1}=R W A_{2}=\frac{E\left[A \mid f_{L}\right]-D-C_{L}-C_{H}}{\sigma_{A} E\left[A \mid f_{L}\right]}$, as the bank does not readjust its expectations regarding the returns of long term risky assets. Even though the bank can observe a negative idiosyncratic shock to asset distribution $f_{R_{L}}$ and/or bad state of fundamentals, the expected losses in long term returns have not yet incurred and thus not accounted for in the book value. In these circumstances, bad fundamentals will not reflect in the accounting value, and so the CoCos will never be converted before low returns are incurred at $t=3$.

In this case, the risk associated with CoCos is much lower than the one priced for, as only in case of bankruptcy $E\left[A \mid f_{L}\right]<D+C_{L}+C_{H}$ the CoCo holders will not recover at least part of their investment.

\subsubsection{Expected credit loss}

We incorporate the expected credit loss by defining the book value as expected returns on assets minus liabilities. At $t=1$, the bank manager incorporates the new expected returns in the capital ratio.

In case of an idiosyncratic shock to the asset distribution, the new book value is: $R W A_{1}=1-\frac{C_{H}+C_{L}+D}{\int_{0}^{1} A \theta f_{L}(\theta) d \theta}<\tau_{H}$. High CoCos are converted. At $t=2$ the bank manager with signal $\theta_{B}$ readjusts the RWA value to: $R W A_{2}\left(\theta_{B}\right)=1-\frac{C_{H}+C_{L}+D}{\int_{\theta_{B}-\varepsilon}^{\theta^{+}-\varepsilon} A \theta f_{L}(\theta) d \theta}$. Note that in the market case the ratio was evaluated at $\theta$ which was the market average, but here only $\theta_{B}$ matters in evaluation. Any fluctuation in $P_{2}^{m}\left(\lambda(\theta), \lambda_{\text {panic }}(\theta)\right)$ will not change the RWA ratio, as it is book based, so investor behavior does not change the manager's response. 
The bank's manager optimization problem at $t=2$ is to maximise share value while maintaining the RWA ratio above $\tau_{L}$ :

$$
\begin{aligned}
& \max _{\beta_{2}, \mathbb{1}_{\text {conv }}} \frac{e_{2}^{b}}{n_{\max }}=\frac{\left(1-\mathbb{1}_{\text {conv }} \beta_{1}\right) E_{2}\left[A \mid f_{L} \wedge \theta_{B}\right]+\mathbb{1}_{\text {conv }} \beta_{2} l-\mathbb{1}_{\text {conv }} C_{L}-D}{n_{\max }} \text { s.t. } \\
& R W A_{2}(\theta)=\frac{e_{2}^{b}}{\left(1-\mathbb{1}_{\text {conv }} \beta_{2}\right) E_{2}\left[A \mid f_{L} \wedge \theta_{B}\right]} \geq \tau_{L}
\end{aligned}
$$

Corollary 7. The bank's best response is independent on the number of equity holders which sell, and is given by an optimal liquidation fraction $\beta_{2, B V}^{*}$, if the risk based ratio is below $\tau_{L} R W A_{1}<\tau_{L}$.

In the intermediate region: $\theta_{L}-\varepsilon<\theta<\theta_{H}+\varepsilon$ the value of waiting minus selling for an investor not hit by liquidity shock is:

$$
v\left(\lambda_{\text {panic }}(\theta)\right)=\left[\frac{E\left[A \mid f_{L}\right]-D-C_{L}}{n_{\max }}-P_{1}^{m}\left(\lambda_{\text {panic }}(\theta)\right) e_{0}\right]
$$

Lemma 3. The decision of equity holders are global strategic substitutes regardless of the type of conversion, as the value of waiting always increases with the share of panicked investors $\left(\frac{\partial v\left(\lambda_{\text {panic }}(\theta)\right)}{\partial \lambda_{\text {panic }}}>0\right)$.

As a consequence, equity holders have no incentive to sell at the intermediate stage, so $\lambda_{\text {panic }}(\theta)=0 \forall \theta \in\left(\theta_{L}+\varepsilon, \theta_{H}-\varepsilon\right)$.

Proposition 5. In case of a book value trigger, the threshold equilibrium $\theta_{B V}^{*}$ below which all equity holders sell is $\theta_{B V}^{*}=\theta_{L}-\varepsilon$. The number of equity holders who sell as a function of fundamentals reported by the bank is:

$$
n_{B V}\left(\theta_{B}, \theta^{*}\right)= \begin{cases}1 & \theta_{B} \leq \theta^{*}-\varepsilon \\ \frac{\theta^{*}-\theta_{B}+\varepsilon}{2 \varepsilon} & \theta^{*}-\varepsilon<\theta_{B}<\theta^{*}+\varepsilon \\ 0 & \theta_{B}>\theta^{*}+\varepsilon\end{cases}
$$

Now the fundamental value of equity, and thus the $R W A$ ratio relies heavily on $\theta_{B}$, the bank's signal. If this is significantly different than the true $\theta$, then CoCos are not a successful bail-in mechanism. A CoCo conversion provides a negative signal to

$$
{ }^{10} \beta_{1, B V}^{*}=\min \left(\left(\frac{D-E\left[A \mid f_{L} \wedge \theta_{B}\right]\left(1-\tau_{L}\right)}{l-E\left[A \mid f_{L} \wedge \theta_{B}\right]\left(1-\tau_{L}\right)}\right)^{+}, 1\right)
$$


market participants and depositors about the asset quality of the bank. Banks have incentives to avoid this stage, and thus they might overstate $\theta_{B}$. It is not incentive compatible for the bank to state their true observed value of the fundamentals. An advantage of this structure is limited market volatility due to lack of excessive trading, as compared to the market based case.

\section{Discussion and Conclusion}

\subsection{CoCo structure comparison}

Figure 10: Book value conversion space

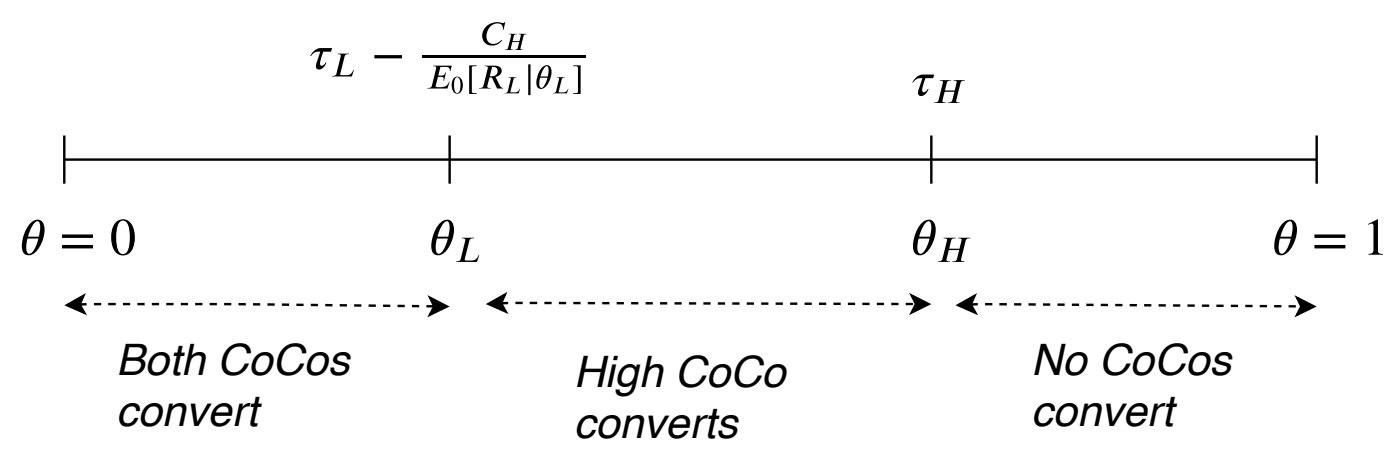

Figure 11: Market value conversion space

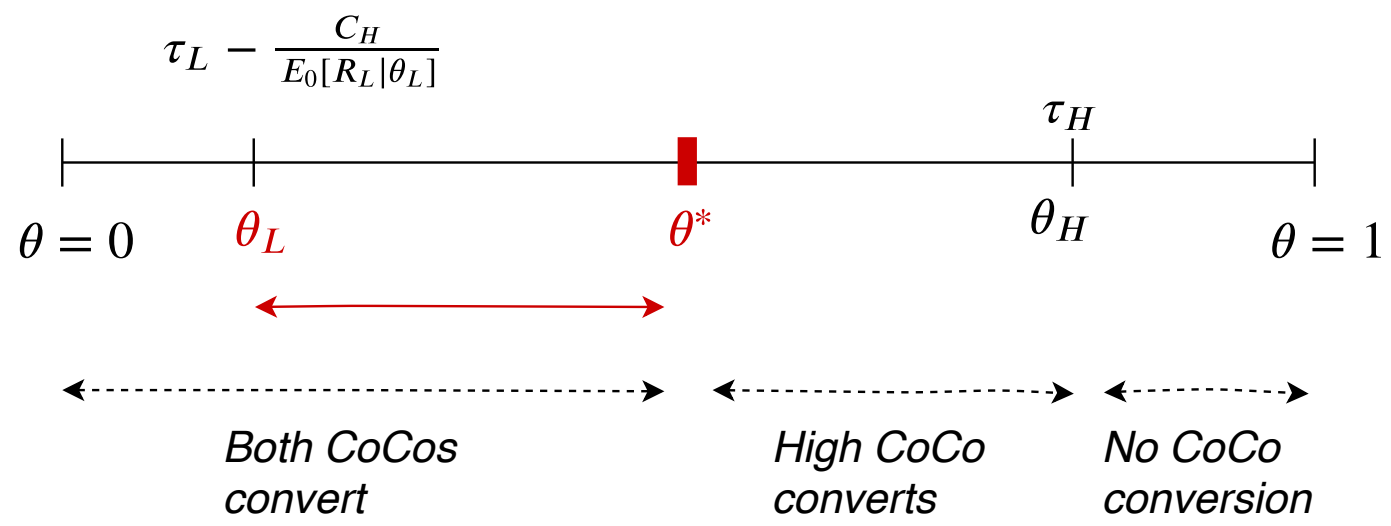


Table 6: Comparison CoCo design

\begin{tabular}{l|cc|cc}
\hline & \multicolumn{2}{|c}{ Market based trigger CoCo } & \multicolumn{2}{c}{ Book based trigger CoCo } \\
\cline { 2 - 5 } & $\begin{array}{c}\text { Dilutive for existing } \\
\text { shareholders }\end{array}$ & $\begin{array}{c}\text { Non-dilutive for } \\
\text { shareholders }\end{array}$ & $\begin{array}{c}\text { Expected } \\
\text { credit loss }\end{array}$ & $\begin{array}{c}\text { Occurred } \\
\text { credit loss }\end{array}$ \\
\hline $\begin{array}{l}\text { Inefficient } \\
\text { conversion }\end{array}$ & Yes & No & Depends & Yes \\
$\begin{array}{l}\text { Relies heavily on } \\
\text { bank's valuation }\end{array}$ & No & No & Yes & Yes \\
$\begin{array}{l}\text { Shareholder strategic } \\
\text { behaviour }\end{array}$ & $\begin{array}{c}\text { Strategic } \\
\text { complements }\end{array}$ & $\begin{array}{c}\text { Strategic } \\
\text { substitutes }\end{array}$ & No & No \\
$\begin{array}{l}\text { Initial capital structure } \\
\text { matters for outcome }\end{array}$ & Yes & Yes & No & No \\
\hline
\end{tabular}

To summarise, in case of a book based trigger with occurred credit losses, the conversion space is given in س. In contrast, the conversion space when both CoCos convert increases when CoCos are dilutive and the trigger is based on market indicators - as depicted in Figure $\mathbf{\square}$.

We further draw a comparison between the four types of CoCos we analysed: market based trigger- dilutive or non-dilutive; occurred losses book value and expected losses book value, conditional on the high trigger CoCo conversion at $t=1$. Throughout the paper we assume deposit insurance, and going concern situations, hence when the bank is still solvent. Thus, it is guaranteed that depositors and senior debt will be repayed. Hence, only $\mathrm{CoCo}$ and equity holders are affected on the bank's side. From a policy perspective, we are concerned with the bail-in capacity of CoCos.

As long as equity holders cannot re-buy their shares, and the wealth transfer benefits shareholders $\psi_{L}<\bar{\psi}_{L}$, market based triggers are an effective bail-in mechanism, in the sense that they are converted when the bank needs them the most. In this case, the investors decisions are strategic substitutes. Nevertheless, this is under the unrealistic assumption that equity cannot re-buy their shares. The same effect can be reached with book value triggers which account for expected losses, as long as the bank correctly assesses the value of its assets. Moreover, this case can bring more flexibility in issuance, as both conversion to equity and principal write-down would reach the same effect from a loss absorption perspective. The wealth effect is 
ambiguous for equity and CoCo holders, and depends on the dilutive properties of CoCos.

In matter of effectiveness, the conversion to equity market trigger CoCos are second to last. We show that they have the highest range of inefficient conversion and early liquidation of long term risky assets, which is dependent on the initial bank capital structure. The CoCo holders have a higher probability of loss due to the strategic complementarities decision of equity holders. Existent shareholders can benefit if face value of conversion offsets its dilutive effects.

The least effective loss absorption mechanism is the book value occurred losses trigger, as it does not have the capacity to absorb losses ex-ante. It is the most beneficial type of CoCos for both equity holders and CoCo holders, as they do not incur losses before the realization of returns or insolvency. An example to support this claim is the write-down of Banco Popular's CoCos in 2017, which was imposed by the regulator once the bank was already insolvent. One can argue that if the conversion would have taken place earlier, the bank could have maintained solvency.

\subsection{Conclusion}

The Swiss government is the first to introduce more stringent capital requirements for systemically important banks, and this is reflected through a mandatory quota on high trigger AT1 CoCos (Swiss Financial Market Supervisory Authority, 20I.5). In this context, this paper focuses on the signalling function of CoCos on the financial state of the issuing ank, and analyses the effects of multiple trigger CoCos on market participants and loss absorption capacities. The most obvious advantage of this structure is the creation of multiple bail-in buffers in case of distress. In contrast, once a conversion is observed, it will subsequently create tensions in the market. An example in that sense is the high share price volatility of Deutsche Bank in 2016, after it was speculated that it cannot meet its CoCo coupons payments. In this paper we argue that there is a trade-off between increased bank resilience and possible fire sales of equity. This damage on a banks' financial stability is a potential unintended consequence of CoCo regulation.

Insofar, CoCo research focused on depositor bank runs, but we argue that equity holder behaviour can influence conversion or asset substitution as well. We develop a model combines cash-in-the-market pricing of equity, noisy market signals about fun- 
damentals, and an idiosyncratic asset shock observed initially only by the bank. We assume a fixed capital structure, and postulate that the bank's aim is to maximise individual value of shares, while meeting the risk based capital regulatory requirements. We evaluate possible CoCo structures, and employ a backward induction equilibrium concept. We solve for the minimum number of equity sellers needed for automatic conversion, and for the unique threshold equilibrium of fundamentals below which shareholders decide to sell. To do so, we draw from the bank run methodology of

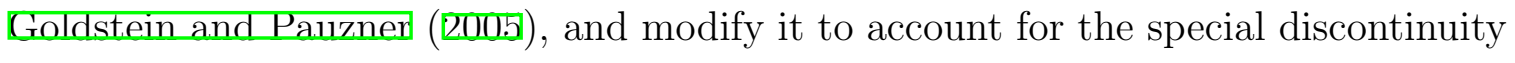
feature created by conversion.

We find that the initial capital structure matters for the scope of inefficient conversions in the market based case triggers. From a social planner perspective, we conclude that market triggers are the least effective. If conversion benefits shareholders, they would have incentives to force inefficient conversion. The dilutive CoCos case $\left(\psi_{L}>\bar{\psi}_{L}\right)$ could lead to 'panic-based' conversions. In contrast, for the book value case, the role of shareholders is limited, and CoCos can act as an effective bail-in mechanism if the bank assesses accurately the asset value and incorporates expected losses in their evaluation. Due to possible underpricing of equity in times of distress or very early inefficient asset substitution, we conclude that the bank has an ex-ante incentive not to issue market based CoCos.

We use the high trigger CoCo conversion as a signalling mechanism, but we argue that similar conclusions are achieved with other types of strong market signals that alert the market on the bank's solvency. For that we refer to the benchmark model. The example has a high degree of generality, and the comparison between the four types of CoCos would still be the same regardless of the type of shock which alerts the market on expected low bank returns. More generally, we provide a formal argument against market based triggers.

Throughout the paper we assume the bank capital structure as fixed, consider simplified types of CoCos and impose additional restrictions for uniqueness of equilibrium. A major point for further research is to determine the optimal capital structure which will minimise the scope of market inefficiencies, and implicitly maximise the capacity of CoCos to act as effective loss absorbing buffers. We talk throughout the paper about low and high triggers, which in practice are very close to each other (5.125\% and $7 \%$ ratio). We aim to further provide a simulation of the model and find a minimum distance between the two triggers that would resolve, or diminish, the 
panic-runs discussed in this paper. Moreover, there is a current debate on the pricing equilibrium of equity, as conversion creates a simultaneity issue which can lead to multiple equillibria. In this paper we simplify the pricing issue through cash in the market pricing and fixed conversion rates, but there is scope for a continuous time analysis in this framework which endogenizes the market price and issuance costs even further. 


\section{References}

Albul, B., Jaffee, D. M., and Tchistyi, A. (2015). Contingent convertible bonds and capital structure decisions. Center for Risk Management Research UC Berkeley.

Allen, F. and Gale, D. (1994). Limited market participation and volatility of asset prices. The American Economic Review, pages 933-955.

Association for Financial Markets in Europe, A. (2016). Prudential data report. eu gsibs prudential capital and liquidity.

Avdijev, S., Bogdanova, B., Bolton, P., Jiang, W., and Kartasheva, A. (2017). Coco issuance and bank fragility. NBER Working Paper Series, (23999):1 - 60.

Avdjiev, S., Bolton, P., Jiang, W., Kartasheva, A., and Bogdanova, B. (2015). Coco bond issuance and bank funding costs. BIS and Columbia University working paper.

Avdjiev, S., Kartasheva, A. V., and Bogdanova, B. (2013). Cocos: a primer. Available at SSRN 2326334.

Beardsworth, T. (2017). Wiped out banco popular creditors question eu on resolution.

Chan, S. and van Wijnbergen, S. (2015). Cocos, contagion and systemic risk. Tinbergen Institute Discussion Paper, (No. 14-110/VI/DSF79).

Chan, S. and van Wijnbergen, S. (2017). Coco design, risk shifting incentives and financial fragility.

Classens, S. (2014). Capital and liquidity requirements: a review of the issues and literature. Yale J. on Reg., 31:735.

Derksen, M., Spreij, P., and van Wijnbergen, S. (2018). Accounting noise and the pricing of coco's. Mimeo, University of Amsterdam.

Diamond, D. W. and Dybvig, P. H. (1983). Bank runs, deposit insurance, and liquidity. The journal of political economy, pages 401-419.

EBAReport (2016). On the monitoring of additional tier 1 (at1) instruments of european union (eu) institutions. , European Banking Authority. 
Glasserman, P. and Nouri, B. (2012). Contingent capital with a capital-ratio trigger. Management Science, 58(10):1816-1833.

Glassserman, P. and Nouri, B. (2016). Demand-deposit contracts and the probability of bank runs. Econometrica, 84(6):2113 - 2153.

Goldstein, I. and Pauzner, A. (2005). Demand-deposit contracts and the probability of bank runs. the Journal of Finance, 60(3):1293-1327.

IFRS9 (2014). Ifrs 9 financial instruments. project summary. Technical report, IFRS.

Kiewiet, G., Lelyveld, I. v., and Wijnbergen, S. v. (2017). Contingent convertibles: Can the market handle them?

Martynova, N. and Perotti, E. (2018). Convertible bonds and bank risk-taking. Journal of Financial Intermediation, 35:61-80.

Morris, S. and Shin, H. S. (1998). Unique equilibrium in a model of self-fulfilling currency attacks. American Economic Review, pages 587-597.

Pennacchi, G. and Tchistyi, A. (2019). On equilibrium when contingent capital has a market trigger: A correction to sundaresan and wang journal of finance (2015). The Journal of Finance, 74(3):1559-1576.

Smith, R. (2017). Coco bond contagion contained after banco popular wipeout. Financial Times.

Sundaresan, S. M. and Wang, Z. (2015). Bank liability structure. Kelley School of Business Research Paper, pages 14-41.

Swiss Financial Market Supervisory Authority, F. (2015). New "too big to fail" capital requirements for global systemically important banks in switzerland. , Swiss Financial Market Suervisory Authority.

Zeng, J. (2014). Contingent capital structure. Technical report, Working Paper. 


\section{A Proofs of lemmas and propositions}

\section{A.1 Proof of Proposition $\square$}

It can trivially be seen that the value of equity is decreasing in liquidation value $\beta$. Thus, the max problem is obtained for binding constraint in $(\boldsymbol{\nabla})$ :

$$
\begin{aligned}
& \frac{P^{m}\left(\lambda(\theta), \lambda_{\text {panic }}(\theta)\right) \cdot n_{\text {max }}}{(1-\beta) E_{t=1}\left[A \mid f_{L}\right]}=\tau_{L} \Longleftrightarrow \\
& \frac{\left[1-\lambda(\theta)-\lambda_{\text {panic }}(\theta)\right] c}{\frac{\left[\lambda(\theta)+\lambda_{\text {panic }}(\theta)\right] e_{0} \cdot n_{\max }}{(1-\beta) E_{t=1}\left[A \mid f_{L}\right]} n_{\text {max }}}=\tau_{L} \Longleftrightarrow \\
& \beta^{*}\left(\lambda(\theta), \lambda\left(\theta_{1}\right)\right)=1-\frac{\left[1-\lambda(\theta)-\lambda_{\text {panic }}(\theta)\right] c}{\tau_{L}\left[\lambda(\theta)+\lambda_{\text {panic }}(\theta)\right] e_{0} E_{1}\left[A \mid f_{L}\right]}
\end{aligned}
$$

From the bank manager perspective, the indifference point between conversion and liquidation is at:

$$
\frac{\left(1-\beta^{*}\right) E_{1}\left[A \mid f_{L}\right]+\beta^{*} l-C_{L}-D}{1+\psi_{H} C_{H}}=\frac{E_{1}\left[A \mid f_{L}\right]-D}{1+\psi_{H} C_{H}+\psi_{L} C_{L}}
$$

Plugging in $\beta^{*}\left(\lambda(\theta), \lambda\left(\theta_{1}\right)\right)$ and solving for $\lambda_{\text {panic }}(\theta)$ immediately yields the threshold $\lambda_{\text {panic }}^{*}(\theta)$ from proposition $\mathbf{\square}$.

\section{A.2 Derivation of Corollary}

The neutral conversion, with a zero wealth transfer between equity holders and CoCo holders is given at the point where the share value in case of conversion is the same as under optimal liquidation:

$$
\frac{\left(1-\beta_{C}^{*}\right) E_{1}\left[A \mid f_{L}\right]+\beta_{C}^{*} l-D}{1+\psi_{H} C_{H}+\psi_{L} C_{L}}=\frac{\left(1-\beta^{*}\right) E_{1}\left[A \mid f_{L}\right]+\beta^{*} l-C_{L}-D}{1+\psi_{H} C_{H}}
$$

Rewriting the function in terms of $\psi_{L}$ yields the result from the corollary.

\section{A.3 Solution of Proposition [}

The condition for an interior solution is given by the following system of equations:

$$
\left\{\begin{array}{l}
0<\frac{\left(1-\lambda(\theta)-\lambda_{\text {panic }}(\theta) c\right.}{\left(\lambda(\theta)+\lambda_{\text {panic }}(\theta) e_{0} \tau_{L} E_{1}\left[A \mid f_{L}\right]\right.}<1 \\
0<\lambda_{\text {panic }}(\theta)<1-\lambda(\theta)
\end{array}\right.
$$

This system of inequalities, alongside with economic sensible assumptions, such as $E_{1}\left[A \mid f_{L}\right]>0$ and $0<\tau_{L}<1$ is solved for: 


$$
\left(e_{0}>0 \wedge E_{1}\left[A \mid f_{L}\right]>0 \wedge 0<\lambda_{\text {panic }}(\theta)<1-\lambda(\theta) \wedge 0<c<\frac{e_{0} E_{1}\left[A \mid f_{L}\right] \tau_{L}\left(\lambda(\theta)+\lambda_{\text {panic }}(\theta)\right)}{1-\lambda(\theta)-\lambda_{1}(\theta)}\right)
$$

Note that $e_{0}+c=W$ from the initial portfolio allocation. Thus, the maximum amount of cash in the market, as a function of expected returns is given by:

$$
c=\frac{E_{1}\left[A \mid f_{L}\right] \tau_{L} W\left(\lambda(\theta)+\lambda_{1}(\theta)\right)}{1-\lambda(\theta)-\lambda_{\text {panic }}(\theta)+\left(\lambda(\theta)+\lambda_{1}(\theta)\right) E_{t=1}\left[A \mid f_{L}\right] \tau_{L}}
$$

Alternatively, we can write the solution to the system as:

$$
\begin{aligned}
& 0<E_{1}\left[A \mid f_{L}\right] \leq \frac{(1-\lambda(\theta)) c}{\lambda(\theta) \tau_{L}(W-c)} \wedge \frac{c \lambda(\theta)-c \lambda(\theta) E_{1}\left[I \mid R_{L}\right] \tau_{L}-c+\lambda(\theta) E_{1}\left[A \mid f_{L}\right] \tau_{L} W}{c E_{1}\left[A \mid f_{L}\right] \tau_{L}-c E_{1}\left[A \mid f_{L}\right] \tau W}<\lambda_{1}<1-\lambda \\
& \vee \\
& E_{1}\left[A \mid f_{L}\right]>\frac{c \lambda-c}{c \lambda \tau_{L}-\lambda \tau_{L} W} \wedge 0<\lambda_{1}<1-\lambda
\end{aligned}
$$

\section{A.4 Existence conditions for Lemma $\square$}

By inserting $\beta^{*}, \beta_{C}^{*}$ and $P^{m}$ in the value of waiting versus selling function, we rewritten as:

$$
v\left(\lambda_{\text {panic }}(\theta)\right)= \begin{cases}-\frac{c\left(D-\frac{1}{\lambda+\lambda_{1}}-l+1\right)+W(r-D)}{c-W}-\frac{c\left(\lambda+\lambda_{1}-1\right)(l-R)}{e_{0} R \tau_{L}\left(\lambda+\lambda_{1}\right)}+C_{L} \\ C_{H} \psi_{H}+1 & \text { if } \lambda_{\text {panic }}(\theta)<\lambda_{\text {panic }}^{*}(\theta) \\ -\frac{D-l\left(\frac{c\left(\lambda+\lambda_{1}-1\right)}{e_{0} R \tau_{L}\left(\lambda+\lambda_{1}\right)}+1\right)+\frac{c\left(\lambda+\lambda_{1}-1\right)}{e_{0} \tau_{L}\left(\lambda+\lambda_{1}\right)}+\frac{c\left(\lambda+\lambda_{1}-1\right)}{\left(\lambda+\lambda_{1}\right)(c-W)}}{C_{H} \psi_{H}+C_{L} \psi_{L}+1} & \lambda_{\text {panic }}(\theta) \geq \lambda_{\text {panic }}^{*}(\theta)\end{cases}
$$

Which further simplify in:

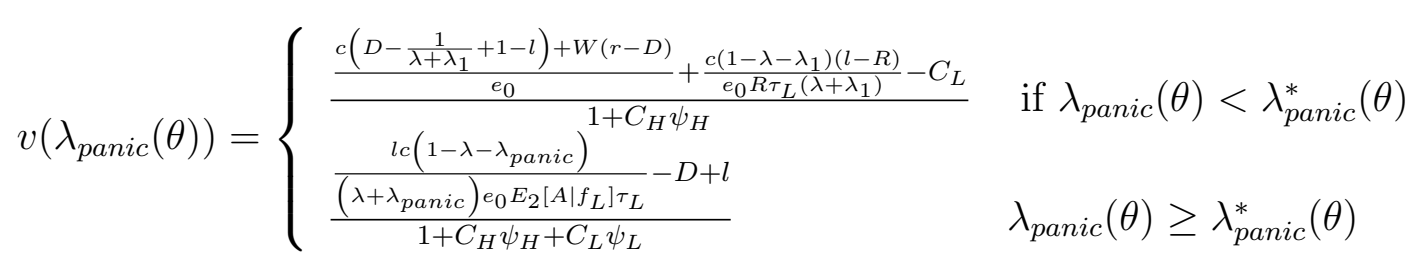

To evaluate the condition for monotonically decreasing piecewise function, we take the partial derivatives in respect to $\lambda_{\text {panic }}(\theta)$, and obtain:

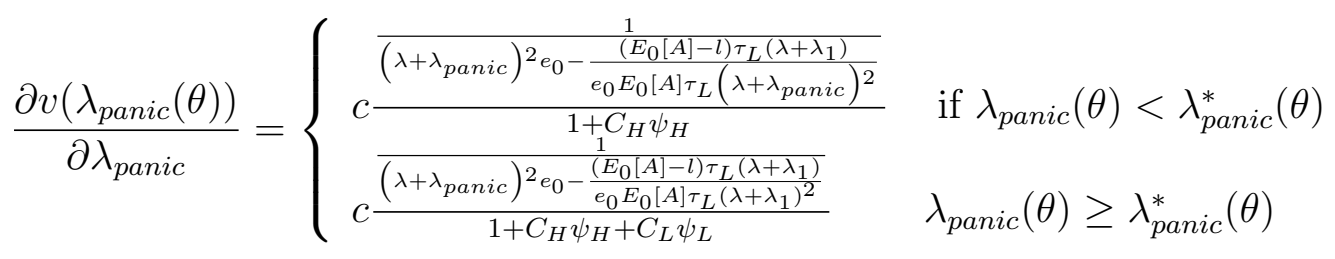

The derivatives have to be negative on both intervals, which simplifies on the entire domain to the following condition: 


$$
\begin{aligned}
& \frac{1}{\left(\lambda+\lambda_{1}\right)^{2} e_{0}}-\frac{\left(E_{0}[A]-l\right) \tau_{L}\left(\lambda+\lambda_{1}\right)}{e_{0} E_{1}\left[A \mid f_{L}\right] \tau_{L}\left(\lambda+\lambda_{1}\right)^{2}}<0 \Longleftrightarrow \\
& 1-\frac{\left(E_{1}\left[A \mid f_{L}\right]-l\right)\left(\lambda_{\text {panic }}+\lambda\right)}{E_{0}\left[A \mid f_{L}\right]}<0 \Longleftrightarrow \\
& E_{1}\left[A \mid f_{L}\right]<\frac{l\left(\lambda_{\text {panic }}+\lambda\right)}{1+\lambda_{\text {panic }}+\lambda}
\end{aligned}
$$

Note that the restriction for strategic complementarities depends on very few parameters: expected value of returns, liquidation value of total assets, and equity sold in the market.

\section{A.5 Condition for non-empty lower dominance region - sec- tion 3}

Under the worst circumstances, all equity holders sell. Thus, the indifference condition between waiting for dividend payments or selling is:

$$
\frac{\int_{\theta_{L}-\varepsilon}^{\theta_{L}+\varepsilon} \theta d F_{R_{L}}(\theta)-D}{1+\psi_{H} C_{H}+\psi_{L} C_{L}}=\frac{\left[1-\lambda(\theta)-\lambda_{\text {panic }}(\theta)\right] c}{\left(\lambda(\theta)+\lambda_{\text {panic }}(\theta) e_{0}\left(1+\psi_{H} C_{H}+\psi_{L} C_{L}\right)\right.}
$$

In the worst case, $\lambda(\theta)+\lambda_{\text {panic }}(\theta)=1$. The integral on the left hand side is a standard Riemann-Stieltjes integral,. Thus we can evaluate it as:

$$
\begin{aligned}
& F\left(\theta_{L}-\varepsilon\right)-F\left(\theta_{L}+\varepsilon\right)-D=0 \Longleftrightarrow \\
& F\left(\theta_{L}-\varepsilon\right)-F\left(\theta_{L}+\varepsilon\right)=D
\end{aligned}
$$

Given that the senior debt $D>0$, the region is trivially non-empty.

\section{A.6 Proof of Theorem $\square$}

Here we briefly reconstruct the two part proof of uniqueness of equilibrium from Gnaldstein and Paunen (2011.0), which uses the single crossing condition. The conditions and the proof follows largely the same structure, except for the discontinuity point between the value of waiting versus selling at the CoCo conversion trigger. Further we modify the proof presented in Goldstein and Paunen (《III. ) pp 1311 to allow for this discontinuity. Please see the complete 3 part proof with the adjoint lemma's in Goldstein and Pallznen (खIII) pp 1311-1314

Part I. If there is an equilibrium, then it is a threshold equilibrium. Strategy profiles 
Let $n\left(\theta, \theta^{\prime}\right)$ be a function that denotes the proportion of agents who sell their equity at signals below $\theta^{\prime}$, and wait for payoffs at $t=2$ otherwise when the true state of nature is $\theta$

$$
n\left(\theta, \theta^{\prime}\right)= \begin{cases}1 & \theta>\theta^{*}+2 \varepsilon \\ \frac{1}{2}+\frac{\theta}{2 \varepsilon} & \theta^{*}-\varepsilon \leq \theta \leq \theta^{*}+\varepsilon \\ 0 & \theta<\theta^{*}-2 \varepsilon\end{cases}
$$

Let $\Delta\left(\theta_{i}, \tilde{n}(n)\right)$ be the utility differential from waiting for payoffs at $t=2$ or selling in $t=1$, when an equity holders observes signal $\theta_{i}$ and holds beliefs $\tilde{n}$. The posterior distribution of $\theta$ is Unif $\left[\theta_{i}-\varepsilon, \theta_{i}+\varepsilon\right]$. By treating $\tilde{n}$ as a number, we can write the utility differential as:

$$
\Delta\left(\theta_{i}, n(\theta)\right)=\frac{1}{2 \varepsilon} \int_{\theta_{i}-\varepsilon}^{\theta_{i}+\varepsilon} v(n(\theta)) d \theta
$$

where

$$
F_{\theta}(n)=\operatorname{prob}[\tilde{n}(\theta) \leq n]
$$

This utility differential is the average of the value of waiting over the uncertainty range $\left[\theta_{i}-\varepsilon, \theta_{i}+\varepsilon\right] . \Delta\left(\theta_{i}, n()\right)$ is always negative in the lower dominance region $\theta^{\prime}<\theta_{L}-\varepsilon$, and always non-negative in the upper dominance region $\theta^{\prime}>\theta_{U}+\varepsilon$. $\theta^{\prime}$ is an equilibrium is any value below $\theta^{\prime}$ gives a negative utility differential, and any value above gives a larger utility differential than the indifference point. Note that unlike global strategic complementarities, the utility differential after the single crossing does not necessarily have to be positive.

At a discontinuity point caused by conversion, the utility differential will be the sum of the region before conversion, and the region after.

Lemma 1: (i) $\Delta\left(\theta_{i}, n()\right)$ is piecewise continuous in $\theta_{i}$ for intervals $\left(\lambda(\theta), \lambda^{*}(\theta)\right)$ and $\left.\left(\lambda^{*}(\theta)\right), 1\right]$ where $\lambda^{*}(\theta)$ is the threshold at which the bank is indifferent between converting and liquidating. (ii) Monotonic transformations make the function continuous and nondecreasing. (iii) Function $\Delta\left(\theta_{i}, n()\right)$ is strictly increasing is $\theta_{i}<\theta_{H}+\varepsilon$ and $\tilde{n}(\theta)<n^{*}(\theta)$.

The solution concept is a Bayesian equilibrium, where an agent sells at $t=1$ if $\Delta\left(\theta_{i}, \tilde{n}()\right)<0$ and waits otherwise.

Part II. There exists a unique threshold equilibrium.

A threshold equilibrium at $\theta^{*}$ is a unique equilibrium if conditional on all equity holders using the same threshold $\theta^{*}$, it is optimal for the agent to sell its shares if he observes a signal $\theta_{i}<\theta^{*}$, and otherwise wait for residual payments at $t=2$.

At this stage Goldstein and Pauner (피.5) show that there is exactly one threshold equilibrium by continuity of $\Delta\left(\theta_{i}, n()\right)$. We escape the lack of continuity in our model, by imposing the additional conditions from Proposition $\boldsymbol{B}$, which ensure single 
crossing of the utility differential. The proof of uniqueness follows the steps pre-

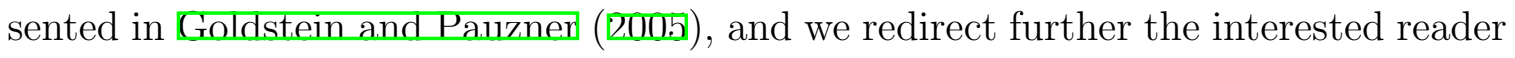
to pages $1313-1324$.

\section{A.7 Derivation of Corollary $\mathbf{6}$}

There is never a conversion choice at $t=2$ if and only if $R W A_{1}>\tau_{H} \forall \theta \in(0,1]$. Let $\delta$ be the admissible lower bound of expected returns on long term assets, with a direct correspondence to $\theta$, through $\int_{\theta-\varepsilon}^{\theta+\varepsilon} \theta f_{R_{L}}(\theta) d \theta=\delta$. The condition must hold even for the worst case of fundamentals, thus also for $\delta$. At $\theta$, the condition reads:

$$
\begin{aligned}
& \frac{\left(1-\beta_{0}\right) \delta+\beta_{0} l-C_{L}-C_{H}-D}{\left(1-\beta_{0}\right) \delta}>\tau_{H} \Longleftrightarrow \\
& \beta_{0}>\frac{C_{H}+C_{L}+D-\delta\left(1-\tau_{H}\right)}{l-\delta\left(1-\tau_{H}\right)}
\end{aligned}
$$

\section{A.8 Proof of Proposition 3}

We succinctly present a proof by contradiction which simultaneously shows part (i) and (ii) of the proposition.

I. Let us assume that there is a unique $\lambda_{\text {panic }}^{s}(\theta) \in(0,1-\lambda(\theta))$ such that $v\left(\lambda_{\text {panic }}^{s}(\theta)\right)=0$ if $\lambda_{1}(\theta)<\lambda_{\text {panic }}^{*}(\theta)$ and $\lambda_{2}(\theta)>\lambda_{\text {panic }}^{*}$. By definition, there are only two candidate solutions for $\lambda_{\text {panic }}^{s}:\left\{\lambda_{1}, \lambda_{2}\right\}$. Thus, the first condition insures that $v\left(\lambda_{1}(\theta)\right)=0$ exists in the admissible space, for any given $\theta$ :

$$
\frac{\left(1-\beta^{*}\right) E_{1}\left[A \mid f_{L}\right]+\beta^{*} l-C_{L}-D}{1+\psi_{H} C_{H}}-\frac{\left[1-\lambda(\theta)-\lambda_{1}(\theta) c\right]}{\left[\lambda(\theta)+\lambda_{1}(\theta) e\left(1+\psi_{H} C_{H}\right)\right.}=0
$$

Similarly, the second condition reads that $v\left(\lambda_{2}(\theta)\right)=0$ is well-defined for any given $\theta$ :

$$
\frac{\left(1-\beta_{\text {conv }}^{*}\right) E_{1}\left[A \mid f_{L}\right]+\beta_{c o n v}^{*} l-D}{1+\psi_{H} C_{H}+\psi_{L} C_{L}}-\frac{\left[1-\lambda(\theta)-\lambda_{2}(\theta) c\right]}{\left[\lambda(\theta)+\lambda_{2}(\theta) e\left(1+\psi_{H} C_{H}+\psi_{L} C_{L}\right)\right.}=0
$$

Hence, there are two points $\lambda_{\text {panic }}^{s}(\theta) \in(0,1-\lambda(\theta))$ such that $v\left(\lambda_{\text {panic }}^{s}(\theta)\right)=0$, for a given $\theta$. But this contradicts our initial assumption that single crossing holds under the above mentioned conditions. Thus, at least one of them cannot hold true.

II. Alternatively, let us assume that we have one unique $\lambda_{\text {panic }}^{\text {s }}(\theta)$ if $\lambda_{1}(\theta)>$ $\lambda_{\text {panic }}^{*}(\theta)$ and $\lambda_{2}(\theta)<\lambda_{\text {panic }}^{*}(\theta)$. Both conditions guarantee that $\lambda_{1}(\theta), \lambda_{2}(\theta)$ are not in the admissable space where $v\left(\lambda_{\text {panic }}(\theta)\right.$ is defined. Thus, neither one of the candidate solutions is viable, so $\lambda_{\text {panic }}^{s}(\theta)=\emptyset$. This result again contradicts our assumption. Hence at least one of the two conditions does not hold. 
Combining the results from $I$ and $I I$, we have only two possible admissible sets which permit single crossing:

$$
\left\{\begin{array}{l}
\lambda_{1}(\theta) \leq \lambda_{\text {panic }}^{*}(\theta) \\
\lambda_{2}(\theta)<\lambda_{\text {panic }}^{*}(\theta)
\end{array}\right.
$$

or

$$
\left\{\begin{array}{l}
\lambda_{1}(\theta)>\lambda_{\text {panic }}^{*}(\theta) \\
\lambda_{2}(\theta) \geq \lambda_{\text {panic }}^{*}(\theta)
\end{array}\right.
$$

The first one gives the single crossing condition before conversion, and the second one insures that the single crossing happens after conversion. 